\title{
High capacity manganese layered-perovskite cathode for fluoride ion batteries involving cationic and anionic redox reaction
}

Hidenori Miki

Toyota Motor Corporation

Kentaro Yamamoto

Kyoto University

Hiroyuki Nakaki

Kyoto University

Takahiro Yoshinari

Kyoto University

Koji Nakanishi

Kyoto University

Shinji Nakanishi

Toyota Motor Corporation

Hideki lba

Toyota motor corporation

Jun Miyawaki

The University of Tokyo

Yoshihisa Harada

The University of Tokyo

Masayuki Ochi

Osaka University

Kazuhiko Kuroki

Osaka University

Tomoki Uchiyama

Kyoto University

Toshiki Watanabe

Kyoto University

Toshiyuki Matsunaga

Kyoto University

Hiroshi Kageyama

Kyoto University https://orcid.org/0000-0002-3911-9864

Yoshiharu Uchimoto ( $\square$ uchimoto.yoshiharu.2n@kyoto-u.ac.jp ) 


\section{Physical Sciences - Article}

Keywords: manganese layered-perovskite cathode, fluoride ion batteries, cationic and anionic redox reaction, high energy storage systems

Posted Date: September 28th, 2020

DOI: https://doi.org/10.21203/rs.3.rs-79936/v1

License: (c) (1) This work is licensed under a Creative Commons Attribution 4.0 International License. Read Full License 


\section{High capacity manganese layered-perovskite cathode for}

\section{fluoride ion batteries involving cationic and anionic redox}

\section{reaction}

Hidenori Miki ${ }^{2} \uparrow$, Kentaro Yamamoto ${ }^{2}$, Hiroyuki Nakaki ${ }^{2}$, Takahiro Yoshinari ${ }^{2}$, Koji

Nakanishi ${ }^{2}$, Shinji Nakanishi' ${ }^{1}$, Hideki Iba ${ }^{1}$, Jun Miyawaki ${ }^{3,4}$, Yoshihisa Harada ${ }^{3,4}$,

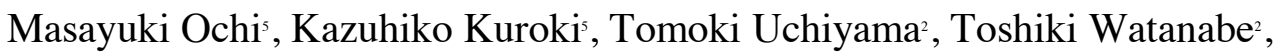

Toshiyuki Matsunaga ${ }^{2}$, Hiroshi Kageyama ${ }^{6} \dagger$, and Yoshiharu Uchimoto ${ }^{2} \dagger$

1 Toyota Motor Corporation, Advanced Material Engineering Division, Higashifuji Technical Center, 1200 Mishuku, Susono, Shizuoka 410-1193, Japan,

${ }^{2}$ Graduate School of Human and Environmental Studies, Kyoto University, Sakyo-ku, Kyoto 606-8501, Japan

${ }^{3}$ Institute for Solid State Physics, The University of Tokyo, Kashiwa, Chiba 277-8581, Japan

4 Synchrotron Radiation Research Organization, The University of Tokyo, Hongo, Bunkyo-ku, Tokyo 113-8656, Japan

${ }^{5}$ Department of Physics, Osaka University, 1-1 Machikaneyama-cho, Toyonaka, Osaka, 560-0043, Japan

${ }^{6}$ Department of Energy and Hydrocarbon Chemistry, Graduate School of Engineering, Kyoto University, Nishikyo-ku, Kyoto 615-8510, Japan

$\dagger$; These authors contributed equally to this work. 


\begin{abstract}
$\underline{\text { Abstract }}$
Developing electrochemical high-energy storage systems is of crucial importance towards a green and sustainable energy supply. A promising candidate is fluoride ion batteries (FIBs), which can deliver a higher energy density than is possible with lithium ion batteries ${ }^{1.2}$. However, conversion-type reactions with metal fluorides causes a poor electrochemical reversibility ${ }^{13.4}$. Recently, layered perovskite oxides such as $\mathrm{LaSrMnO}_{4}$ have been shown to undergo topotactic electrochemical (de)fluorination, but they have low reversible discharge capacities $(25 \sim 100 \mathrm{mAh} / \mathrm{g})$ and poor rate capabilities. Here we show that a double-layered perovskite oxyfluoride $\mathrm{La}_{12} \mathrm{Sr}_{1.8} \mathrm{Mn}_{2} \mathrm{O}_{1-5} \mathrm{~F}_{2}$ exhibits topotactic (de)intercalation reaction inside the rock-salt slabs, achieving a large reversible capacity of $535 \mathrm{mAh} / \mathrm{cm}^{3}\left(0 \leq x \leq 2\right.$ in $\left.\mathrm{La}_{12} \mathrm{Sr}_{18} \mathrm{Mn}_{2} \mathrm{O}_{7-8} \mathrm{~F}_{x}\right)$, with excellent cycle stability and rate capability. Surprisingly, despite the close-packed perovskite-based structure, two extra fluoride ions are (de)intercalated beyond $x=2$, leading to a reversible capacity of $1168 \mathrm{mAh} / \mathrm{cm}^{3}(0 \leq x \leq 4)$. During the further intercalation, oxygen molecules are formed in the perovskite layer, as in $\mathrm{Na}_{075}\left[\mathrm{Li}_{025} \mathrm{Mn}_{0.75}\right] \mathrm{O}_{2}^{5}$, which is responsible for the charge compensation (i.e. anion redox) ${ }^{5.6}$ and the concomitant formation of oxygen vacancies that allow the incorporation of the excess fluoride ions. These results highlight the layered perovskite oxide/oxyfluorides as a new class of active materials for the construction of high-performance FIBs. More generally, the concept of anion-intercalation through $\mathrm{O}_{2}$ formation in the mixed-anion perovskite materials can be used to develop new functionalities.
\end{abstract}




\section{Introduction}

Considerable efforts have been devoted to developing efficient energy storage systems in order to achieve a green and sustainable energy society in the future. The widespread success of lithium-ion rechargeable batteries (LIBs) is attributed to their high energy density, light weight, long-term durability, and the presence of a large number of available host structures? . In recent years, special attention has been paid to enhancing the capacity of cathode materials through the redox of oxide anions (including the formation of $\mathrm{O}^{+}, \mathrm{O}_{2}^{2}, \mathrm{O}_{2}^{-}$, and even $\mathrm{O}_{2}$ ), in addition to the redox of transition metal cations ${ }^{5,6.815}$. However, there is a growing demand for electric vehicles with longer mileage and grid energy storage, for which developing larger power source is required.

In order to meet these requirements, various types of batteries (e.g., all-solid-state, air battery type, redox flow type) using different carrier ions (e.g., $\mathrm{Li}^{+}, \mathrm{Na}^{+}, \mathrm{Mg}^{2}, \mathrm{Cl}^{-}$, $\mathrm{F}^{-}$) have been proposed ${ }^{1.625}$. Among them, fluoride ion batteries (FIBs) with fluoride ions working as a carrier are highly promising with respect to theoretical high energy densities $^{14}$. The highest electronegativity of fluorine as well as high redox potential $2.87 \mathrm{~V}$ (vs. SHE) of $\mathrm{F}-\mathrm{F}_{2}\left(c f .1 .36 \mathrm{~V}\right.$ for $\mathrm{Cl} / \mathrm{Cl}_{2}, 0.54 \mathrm{~V}$ for $\left.\mathrm{I} / \mathrm{I}_{2}\right)$ allow the wide electrochemical potential window, leading to high voltage batteries ${ }^{26}$. A high 
electrochemical capacity per weight in conversion-type fluorine-rich compounds (e.g., $\left.\mathrm{CuF}_{2}, \mathrm{BiF}_{3}, \mathrm{MgF}_{2}\right)$ is also an advantage ${ }^{134}$. However, a drastic decrease in electronic conductivity and a large volume change during charge-discharge process seriously impairs rate capability and cycle stability.

For these reasons, as an alternative to the conversion type, the search for electrode candidates from materials capable of topotactic fluorine intercalation ${ }^{273 .}$ appears to be promising, as has been with the case of LIBs (e.g., $\mathrm{LiCoO}_{2}^{32}$ and $\mathrm{LiCo}_{13} \mathrm{Ni}_{13} \mathrm{Mn}_{13} \mathrm{O}_{2^{33}}$ ). O. Clemens et al. showed electrochemical topotactic fluorinations, using $\mathrm{LaSrMnO}_{4}{ }^{34}$ $\mathrm{La}_{2} \mathrm{CoO}_{4}{ }^{35}$ and more recently $\mathrm{La}_{13} \mathrm{Sr}_{1: 3} \mathrm{Mn}_{2} \mathrm{O}_{7}^{36}$ with a Ruddlesden-Popper perovskite structure of $A_{n+1} B_{n} \mathrm{O}_{3 n+1}(n=1,2)$, in which $A$ is a rare-earth or alkaline earth element and $B$ is a transition metal. Unfortunately, they all exhibited low reversible discharge capacities of $100 \mathrm{mAh} / \mathrm{g}\left(\sim 1.3 \mathrm{~F}^{-}\right.$per $\left.\mathrm{LaSrMnO}_{4}\right), 60 \mathrm{mAh} / \mathrm{g}\left(\sim 0.9 \mathrm{~F}^{-}\right.$per $\left.\mathrm{La}_{2} \mathrm{CoO}_{4}\right), 25$ $\mathrm{mAh} / \mathrm{g}\left(\sim 0.5 \mathrm{~F}^{-}\right.$per $\left.\mathrm{La}_{13} \mathrm{Sr}_{1,7} \mathrm{Mn}_{2} \mathrm{O}_{7}\right)$. The achieved rate capability is also low for all materials, with poor discharge capacities even at low current densities of $2.4 \sim 12$ $\mu \mathrm{A} / \mathrm{cm}^{2}$ at $150 \sim 200{ }^{\circ} \mathrm{C}$.

In this study, we demonstrate that $\mathrm{La}_{12} \mathrm{Sr}_{18} \mathrm{Mn}_{2} \mathrm{O}_{7} \mathrm{~F}_{2}$ is able to electrochemically deintercalate (and intercalate) two fluoride ions by fully utilizing the interstitial site in 
the rock-salt slab, with excellent cycle performance (80\% capacity retention after 50 cycles) and rate capability (60 mAh/g at $100 \mathrm{~mA} / \mathrm{g})$. Unexpectedly, $\mathrm{La}_{12} \mathrm{Sr}_{18} \mathrm{Mn}_{2} \mathrm{O}_{7} \mathrm{~F}_{2}$ can be further topotactically fluorinated to a capacity density of $1168 \mathrm{mAh} / \mathrm{cm}^{3}$, allowing the development of FIBs with high energy density and durability. Interestingly, these excess fluoride ions are introduced into the perovskite slabs, where the charge compensation and space creation is achieved through the formation of molecular $\mathrm{O}_{2}$ (i.e., anion redox), as found in LIBs and sodium ion batteries ${ }^{56,8,123738}$. Given the abundance of perovskite compounds, these results are expected to facilitate the development of cathode materials for FIBs, as mixed-anion compounds with anion redox could be applied to active materials. 


\section{$\underline{\text { Results and Discussion }}$}

\section{Structural characterization of $\mathrm{La}_{1.2} \mathrm{Sr}_{1.8} \mathrm{Mn}_{2} \mathrm{O}_{7} \mathbf{F}_{2}$}

We employed a chemically fluorinated $\mathrm{La}_{12} \mathrm{Sr}_{18} \mathrm{Mn}_{2} \mathrm{O}_{7} \mathrm{~F}_{2}$ as a starting cathode active material. According to the previous report ${ }^{30}, \mathrm{La}_{12} \mathrm{Sr}_{18} \mathrm{Mn}_{2} \mathrm{O}_{7}$ was fluorinated using polyvinylidene difluoride. X-ray diffraction (XRD) data (Supplementary Figure 1)

yielded tetragonal $(\mathrm{I} / \mathrm{mmm})$ cell parameters $(a=3.88065(7) \AA$, $c=20.1203(4) \AA$ for $\mathrm{La}_{12} \mathrm{Sr}_{1.8} \mathrm{Mn}_{2} \mathrm{O}_{7}$ and $a=3.7956(3) \AA, c=23.349(2) \AA$ for $\mathrm{La}_{12} \mathrm{Sr}_{18} \mathrm{Mn}_{2} \mathrm{O}_{7} \mathrm{~F}_{2}$ ) that are consistent with those reported ${ }^{30}$. The observation with Spherical Aberration (Cs) corrected Scanning Transmission Electron Microscope (Cs-corrected STEM) for these samples are also consistent with the reported structures, while atomic-resolution electron energy loss spectroscopy (EELS) for $\mathrm{La}_{12} \mathrm{Sr}_{18} \mathrm{Mn}_{2} \mathrm{O}_{7} \mathrm{~F}_{2}$ revealed the fluorine insertion at the interstitial site in the rock-salt block (Supplementary Figures 2, 3). Observation by Scanning Electron Microscopy (SEM) show that the shape and size of the primary particles $(1 \sim 3 \mu \mathrm{m})$ are retained after chemical fluorination (Supplementary Figure 4). 


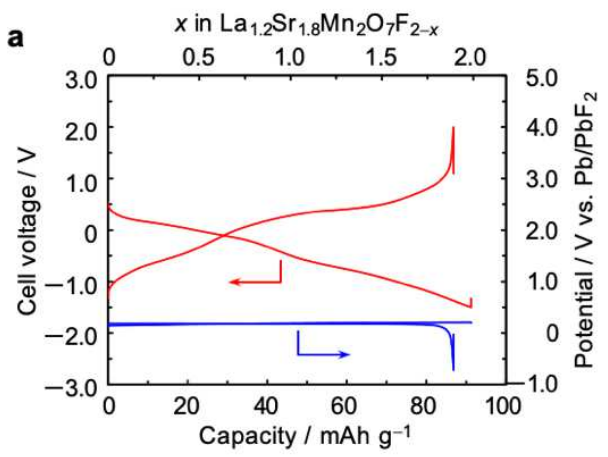

b

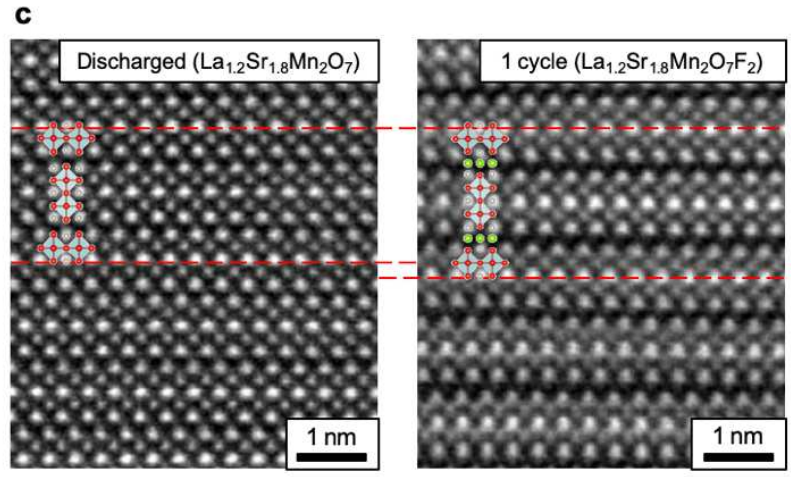

d

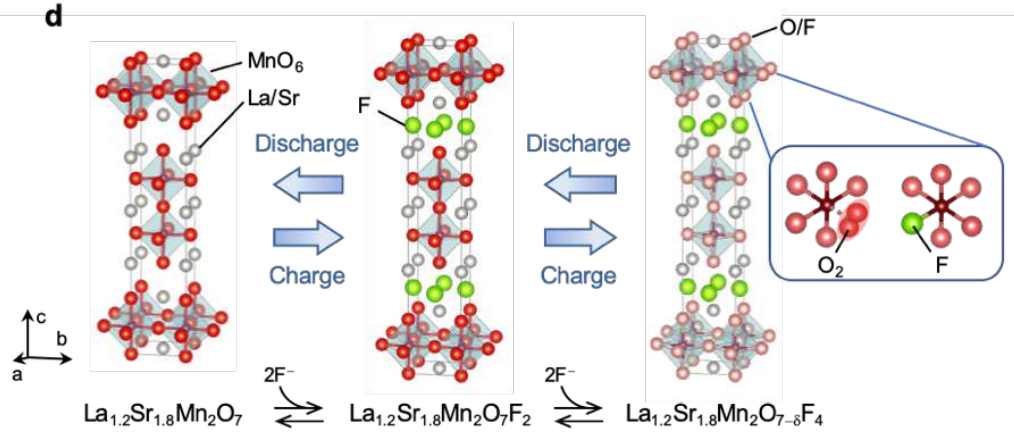

Figure 1 I Electrochemical performance of $\mathrm{La}_{12} \mathrm{Sr}_{18} \mathrm{Mn}_{2} \mathrm{O}_{7} \mathrm{~F}_{2}$ and structural changes after discharge/charge process. a, Discharge/charge curves at a rate of $10 \mathrm{~mA} / \mathrm{g}$ at $140{ }^{\circ} \mathrm{C}$, where red and blue lines show, respectively, cell voltage and potential of counter electrode. $\mathbf{b}$, XRD patterns of cathode composites containing $\mathrm{La}_{12} \mathrm{Sr}_{18} \mathrm{Mn}_{2} \mathrm{O}_{7} \mathrm{~F}_{2}$ before and after galvanostatic discharge/charge. Red and black broken lines are peaks of $\mathrm{La}_{12} \mathrm{Sr}_{18} \mathrm{Mn}_{2} \mathrm{O}_{7} \mathrm{~F}_{2}$ and $\mathrm{La}_{12} \mathrm{Sr}_{18} \mathrm{Mn}_{2} \mathrm{O}_{7}$, respectively. Asterisk marks $\mathrm{La}_{0,9} \mathrm{Ba}_{0.1} \mathrm{~F}_{29}$ (solid electrolyte). c, High-angle annular dark-field (HAADF) STEM images of $\mathrm{La}_{12 .} \mathrm{Sr}_{1.8} \mathrm{Mn}_{2} \mathrm{O}_{7} \mathrm{~F}_{2}$ after discharge and 1 cycle viewed along [010]. d, Discharge/charge scheme of $\mathrm{La}_{12} \mathrm{Sr}_{18} \mathrm{Mn}_{2} \mathrm{O}_{7} \mathrm{~F}_{2}$. Note that the pristine sample has an oxygen offstoichiometry of $\mathrm{La}_{12} \mathrm{Sr}_{18} \mathrm{Mn}_{2} \mathrm{O}_{7-8} \mathrm{~F}_{2}$ (see text). 


\section{Electrochemical intercalation in rock-salt slabs of $\mathrm{La}_{1.2} \mathrm{Sr}_{1.8} \mathrm{Mn}_{2} \mathrm{O}_{7} \mathbf{F}_{x}(0 \leq x \leq 2)$}

A cathode mixture was prepared by ball-milling $\mathrm{La}_{12} \mathrm{Sr}_{18} \mathrm{Mn}_{2} \mathrm{O}_{7} \mathrm{~F}_{2}$ with $\mathrm{La}_{00} \mathrm{Ba}_{0.1} \mathrm{~F}_{29}$ and Vapor-Grown Carbon Fiber (VGCF), as often used in FIBB ${ }^{3 a, 3}$. A three-electrodes cell was assembled using the mixture, with $\mathrm{Pb}$ wire as a reference electrode by inserting its tip into the solid electrolyte not to contact with each electrode layer. Figure 1a shows discharge-charge profiles in a voltage range of $-1.5 \sim 2.0 \mathrm{~V}$ at $10 \mathrm{~mA} / \mathrm{g}$. Upon the initial discharge, the capacity reached $91.2 \mathrm{mAh} / \mathrm{g}$, which is equivalent to the capacity of two $\mathrm{F}$-anions $(91.7 \mathrm{mAh} / \mathrm{g})$ and suggests an almost complete $\mathrm{F}$ - extraction from the $\mathrm{La}_{12} \mathrm{Sr}_{18} \mathrm{Mn}_{2} \mathrm{O}_{7} \mathrm{~F}_{2}$. Subsequent charge process yielded a capacity of $86.8 \mathrm{mAh} / \mathrm{g}$, corresponding to a discharge-charge efficiency of $95.2 \%$.

Structural changes in the cathode material during the discharge-charge reactions were probed by ex-situ XRD in Ar atmosphere (Figure 1b). Upon discharge, the pristine $\mathrm{La}_{12} \mathrm{Sr}_{18} \mathrm{Mn}_{2} \mathrm{O}_{7} \mathrm{~F}_{2}(I 4 / m m m)$ is transformed to $\mathrm{La}_{12} \mathrm{Sr}_{18} \mathrm{Mn}_{2} \mathrm{O}_{\text {, }}(I 4 / m m m ; a=$ 3.842(2) $\AA, c=20.25(2) \AA$ ), and then, after charging, converted to the original $\mathrm{La}_{12} \mathrm{Sr}_{18} \mathrm{Mn}_{2} \mathrm{O}_{7} \mathrm{~F}_{2}(a=3.781(34) \AA, c=23.32(21) \AA)$. No change of the diffraction peaks in $\mathrm{La}_{0}, \mathrm{Ba}_{0} \mathrm{~F}_{29}$ is observed. HAADF-STEM images (Figure 1c, Supplementary Figure 
5a, 5b) and SAED patterns (Supplementary Figure 5c, 5d) of the $\mathrm{La}_{12} \mathrm{Sr}_{18} \mathrm{Mn}_{2} \mathrm{O}_{7} \mathrm{~F}_{2}$ cathode after discharge and 1-cycle agree with the proposed structures. These observations verify a reversible electrochemical (de)intercalation between $\mathrm{La}_{12} \mathrm{Sr}_{1.8} \mathrm{Mn}_{2} \mathrm{O}_{7} \mathrm{~F}_{2}$ and $\mathrm{La}_{12} \mathrm{Sr}_{1.8} \mathrm{Mn}_{2} \mathrm{O}_{7}$ (Figure 1d). Atomic-resolution STEM-EELS mapping supported the insertion and extraction of fluoride ions, but the atomic contrast (Supplementary Figure 6) is less clear than the pristine $\mathrm{La}_{12} \mathrm{Sr}_{18} \mathrm{Mn}_{2} \mathrm{O}_{7} \mathrm{~F}_{2}$ sample, where all $\mathrm{F}$ - ions in are occupied at the interstitial site of the rock-salt slabs. 

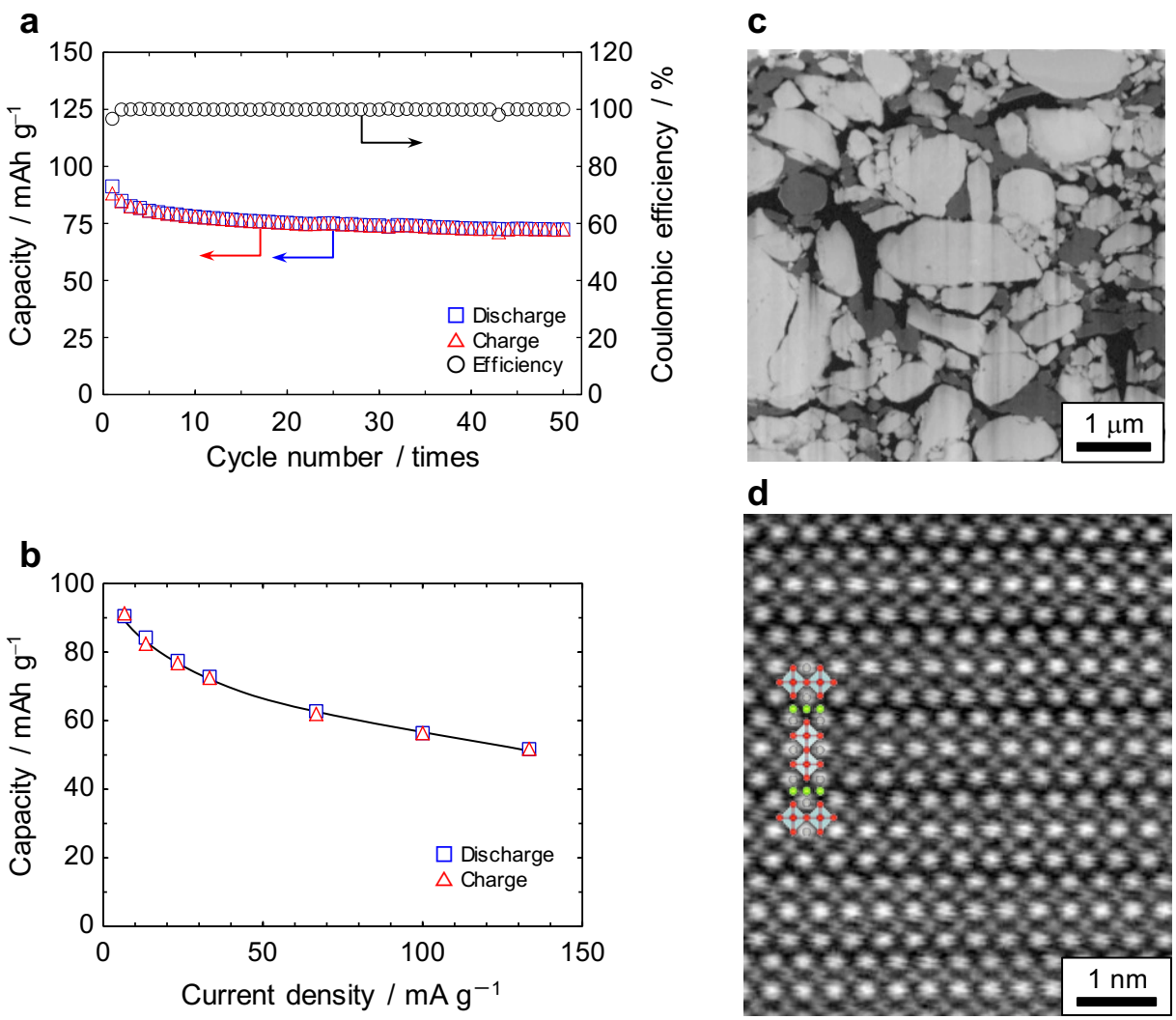

Figure 2 I Cycle stability and rate performance of $\mathbf{L a}_{12} \mathbf{S r}_{18} \mathbf{M n}_{2} \mathrm{O}_{7} \mathbf{F}_{2}$. a, Cycle performance of the discharge and charge capacities and the efficiencies. The efficiencies are estimated by dividing charge capacities by discharge capacities in the same cycle. b, Rate capability of $\mathrm{La}_{12} \mathrm{Sr}_{18} \mathrm{Mn}_{2} \mathrm{O}_{7} \mathrm{~F}_{2}$, which was charged to $2.0 \mathrm{~V}$ at different ratesand then discharged to $-1.5 \mathrm{~V}$ at the same rate as the charge process. $\mathrm{c}$, d, HAADF-STEM images of charged $\mathrm{La}_{12} \mathrm{Sr}_{1.8} \mathrm{Mn}_{2} \mathrm{O}_{7} \mathrm{~F}_{2}$ after 50 cycles, viewed along [010]. Note that the pristine sample has an oxygen off-stoichiometry of $\mathrm{La}_{12} \mathrm{Sr}_{18} \mathrm{Mn}_{2} \mathrm{O}_{7-}$ ${ }_{0} \mathrm{~F}_{2}$ (see text). 
It is remarkable that the electrode $\mathrm{La}_{12} \mathrm{Sr}_{18} \mathrm{Mn}_{2} \mathrm{O}_{7} \mathrm{~F}_{2}$ exhibited excellent cycle stability and rate capability. It maintained capacity retention at $80 \%$ of the initial capacity after 50 cycles, with the coulombic discharge-charge efficiency of almost $100 \%$ during the cycles (Figure 2a). Moreover, even at $100 \mathrm{~mA} / \mathrm{g}$, this electrode has a capacity of $60 \mathrm{mAh} / \mathrm{g}$ (corresponding to $65 \%$ of the discharge capacity at $10 \mathrm{~mA} / \mathrm{g}$ ), despite the relatively large particle size of $1 \sim 3 \mu \mathrm{m}$ (Figure $2 \mathrm{~b}$ ). These properties are distinct from conversion-type active materials (e.g., $\mathrm{CuF}_{2}, \mathrm{BiF}_{3}$ ) whose capacity drops rapidly; in the case of $\mathrm{BiF}_{3}$, it is less than $50 \%$ of the initial discharge capacity after 10 cycles'

The HAADF-STEM images after 50 cycles at charge state (Figure 2c, 2d) resembles those of the pristine sample of $\mathrm{La}_{12} \mathrm{Sr}_{18} \mathrm{Mn}_{2} \mathrm{O}_{7} \mathrm{~F}_{2}$, with no cracks in the active material or voids at the active/solid electrolyte interface in the electrode (Figure 2c, Supplementary Figure 5a, 5b). It may be related to a smaller volume change of our material $(10 \%)$ than reported cathode materials of FIBs (e.g., $\mathrm{CuF}_{2}(173 \%), \mathrm{BiF}_{3}$ (134\%), $\left.\mathrm{LaSrMnO}_{4} \mathrm{~F}_{2-x^{34}}(17 \%), \mathrm{La}_{2} \mathrm{CoO}_{4} \mathrm{~F}_{2-x^{25}}(13 \%)\right)$.

We also conducted electrochemical measurements using $\mathrm{La}_{12} \mathrm{Sr}_{18} \mathrm{Mn}_{2} \mathrm{O}_{7}$ as a starting material and obtained similar charge/discharge curves with excellent cycle stability 
(Supplementary Figure 7). Compared with $\mathrm{La}_{12} \mathrm{Sr}_{18} \mathrm{Mn}_{2} \mathrm{O}_{7} \mathrm{~F}_{2}, \mathrm{XRD}$ and STEM-EELS data (Supplementary Figure 8) show a difference in the 1st charge process, while subsequent cycles are reversible (Supplementary Figure 7), with the charge/discharge profiles similar to those of $\mathrm{La}_{12} \mathrm{Sr}_{18} \mathrm{Mn}_{2} \mathrm{O}_{7} \mathrm{~F}_{2}$. We also found that the Mn $K$-edge shifts to lower energy after the 1st cycle than that of pristine $\mathrm{La}_{12} \mathrm{Sr}_{1.8} \mathrm{Mn}^{3+4}{ }_{2} \mathrm{O}_{7}$ (Supplementary Figure 9), indicating a reduced valence to $\mathrm{Mn}^{3+}$. This implies that the initial $\mathrm{F}$ intercalation to $\mathrm{La}_{12} \mathrm{Sr}_{18} \mathrm{Mn}_{2} \mathrm{O}_{7}$ leads to a partially loss of oxide anions, resulting in $\mathrm{La}_{1.2} \mathrm{Sr}_{1.8} \mathrm{Mn}_{2} \mathrm{O}_{7-8}$. The insertion of two $\mathrm{F}$ - (i.e., redox from $\mathrm{Mn}^{3+}$ to $\mathrm{Mn}^{4}$ ) determines the oxygen vacancy to be around 0.4. Furthermore, the change of $\mathrm{Mn} K$-edge in $\mathrm{La}_{12} \mathrm{Sr}_{1.8} \mathrm{Mn}_{2} \mathrm{O}_{7} \mathrm{~F}_{2}$ from the pristine to the discharged state is similar to that of $\mathrm{La}_{12} \mathrm{Sr}_{1.8} \mathrm{Mn}_{2} \mathrm{O}_{7}$ from the charged to 1-cycled discharged state, suggesting that the pristine oxyfluoride already has oxygen vacancies. Thus, in the following it is referred to as $\mathrm{La}_{12} \mathrm{Sr}_{18} \mathrm{Mn}_{2} \mathrm{O}_{7-8} \mathrm{~F}_{2}(\delta \sim 0.4)$.

\section{Electrochemical further fluorination of $\mathrm{La}_{12} \mathrm{Sr}_{1.8} \mathrm{Mn}_{2} \mathrm{O}_{7-\delta} \mathrm{F}_{x}$} $(0 \leq x \leq 4)$ 
So far, we have demonstrated the excellent performance of electrochemical reactions for $\mathrm{La}_{12} \mathrm{Sr}_{18} \mathrm{Mn}_{2} \mathrm{O}_{7-5} \mathrm{~F}_{x}(0 \leq x \leq 2)$. Although $\mathrm{La}_{12} \mathrm{Sr}_{1.8} \mathrm{Mn}_{2} \mathrm{O}_{7-5} \mathrm{~F}_{2}$ is the terminal F-rich phase available via chemical fluorination ${ }^{2830}$, recent studies on oxides for LIBs successfully utilize oxygen redox chemistry $\left(\mathrm{O}^{2} / \mathrm{O}^{n}\right)$ to achieve extended capacity (e.g., $\left.\mathrm{Li}_{120} \mathrm{Mn}_{0.54} \mathrm{Co}_{0.13} \mathrm{Ni}_{0.13} \mathrm{O}_{2}^{38}, \mathrm{Li}_{2} \mathrm{Ru}_{0.75} \mathrm{Sn}_{0.25} \mathrm{O}_{3}^{8}, \mathrm{Li}_{13} \mathrm{Nb}_{03} \mathrm{Mn}_{0.4} \mathrm{O}_{2}^{12}\right)$. With this in mind, we attempted further fluorination by increasing the upper cut-off potential (from $2.0 \mathrm{~V}$ ) and the results are shown in Figures 3 and Supplementary Figure 10. Here, a cell with $\mathrm{PbF}_{2} / \mathrm{AB}$ (acetylene black) composite (in addition to $\mathrm{Pb}$ foil) was employed on the anode side to allow excess fluoride ions to path through the $\mathrm{La}_{12} \mathrm{Sr}_{18} \mathrm{Mn}_{2} \mathrm{O}_{7-8} \mathrm{~F}_{2}$ cathode. When the electrochemical cell was charged to $3.0 \mathrm{~V}$ after the initial discharge (with a capacity equivalent to two fluoride ions), a wide plateau appeared at around $2.0 \mathrm{~V}$ and the total charge capacity reached about $250 \mathrm{mAh} / \mathrm{g}$ (Figure 3a). The subsequent discharge process delivered a large capacity of $190 \mathrm{mAh} / \mathrm{g}$, twice the capacity of the initial discharge process. Similar results were obtained with $\mathrm{La}_{12} \mathrm{Sr}_{18} \mathrm{Mn}_{2} \mathrm{O}_{7}$ as the starting material (Supplementary Figure 11). 

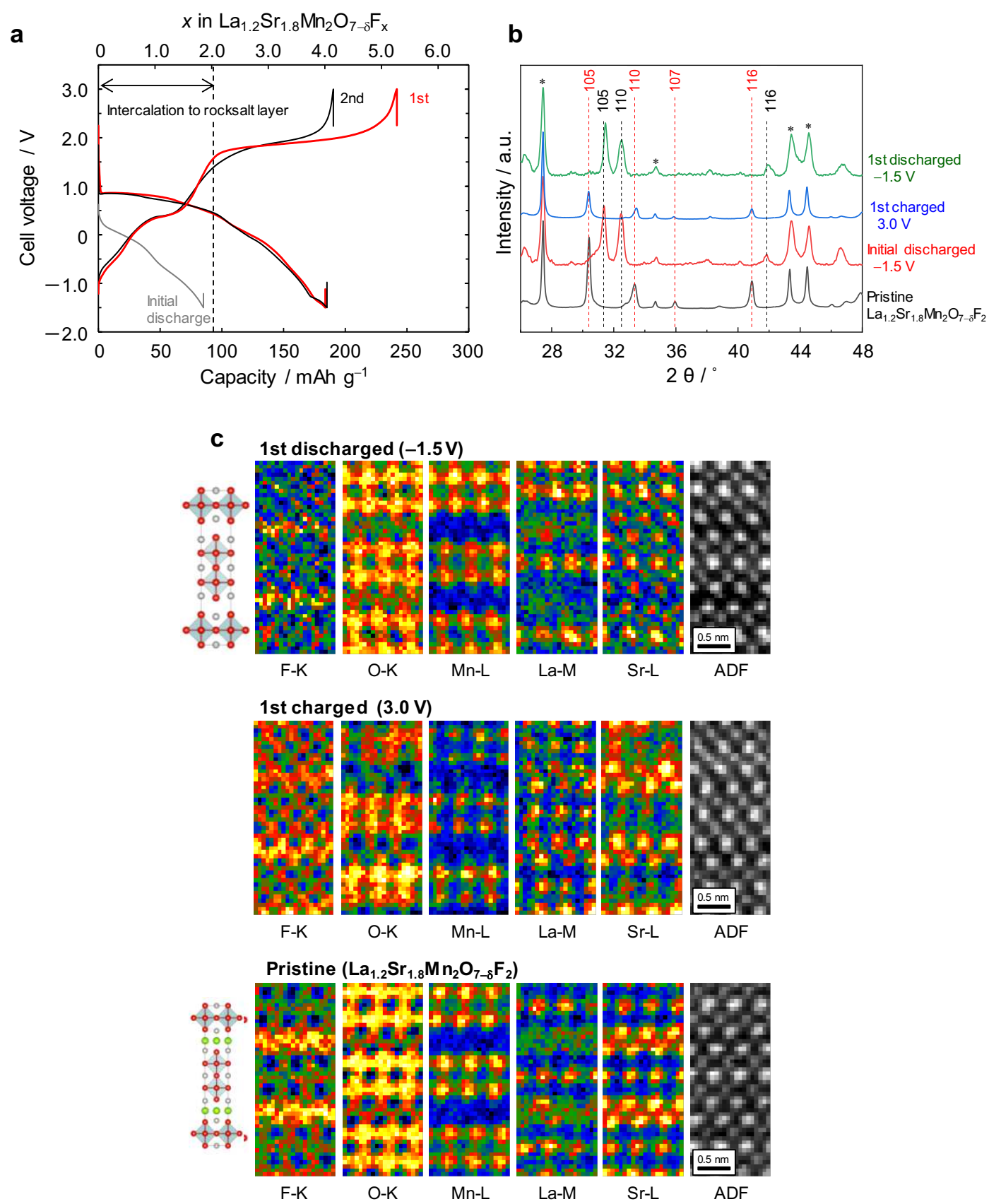

Figure 3 I Charge/discharge properties and structural changes of $\mathrm{La}_{12} \mathrm{Sr}_{18} \mathrm{Mn}_{2} \mathrm{O}_{7-5} \mathrm{~F}_{2}$ upon charging at higher potential. a, Charge/discharge curves at a rate of $10 \mathrm{~mA} / \mathrm{g}$ at $140{ }^{\circ} \mathrm{C}$, where $\mathrm{PbF}_{2} / \mathrm{AB}$ composite was included in the anode side between solid electrolyte and $\mathrm{Pb}$ foil as a fluorine source. $\mathbf{b}, \mathrm{XRD}$ patterns of cathode composites containing $\mathrm{La}_{12} \mathrm{Sr}_{18} \mathrm{Mn}_{2} \mathrm{O}_{7-8} \mathrm{~F}_{2}$ before and after galvanostatic charge/discharge. Red and black broken lines correspond, respectively, to $\mathrm{La}_{12} \mathrm{Sr}_{18} \mathrm{Mn}_{2} \mathrm{O}_{7-8} \mathrm{~F}_{2}$ and $\mathrm{La}_{12} \mathrm{Sr}_{18} \mathrm{Mn}_{2} \mathrm{O}_{7}$. Asterisks denote $\mathrm{La}_{09} \mathrm{Ba}_{0.1} \mathrm{~F}_{29}$ electrolyte. Note that in order to obtain clearer diffraction peaks for $\mathrm{La}_{12} \mathrm{Sr}_{1.8} \mathrm{Mn}_{2} \mathrm{O}_{7-s} \mathrm{~F}_{2}$, we used a cathode composite with higher active material 
content ( $\sim 60 \mathrm{wt} \%$ ) (see Supplementary Figure 12). c, Atomic resolution STEM-EELS mapping images of $\mathrm{La}_{12 .} \mathrm{Sr}_{1.8} \mathrm{Mn}_{2} \mathrm{O}_{7-8} \mathrm{~F}_{2}$ before and after galvanostatic charge/discharge, viewed along [010]. For simplicity, the ideal structures are shown.

This excess electrochemical fluorination is also topotactic; the XRD pattern of the 3.0 V charged $\mathrm{La}_{12} \mathrm{Sr}_{18} \mathrm{Mn}_{2} \mathrm{O}_{7-8} \mathrm{~F}_{2}$ cathode is similar to that of the pristine cathode (Figure $3 \mathrm{~b}$ ), and the ADF images of these cathodes show regular cation arrangements (Figure 3c). Furthermore, the atomic-resolution EELS mapping in the $3.0 \mathrm{~V}$ charged cathode (Figure 3c) shows an excess of fluoride ions in the perovskite block, in addition to the interstitial site in the rock-salt slabs. The intensity of XRD pattern of the $3.0 \mathrm{~V}$ charged cathode is close to that of the pristine $\mathrm{La}_{12} \mathrm{Sr}_{18} \mathrm{Mn}_{2} \mathrm{O}_{7-8} \mathrm{~F}_{2}$. The following discharge process led to the de-fluorinated $\mathrm{La}_{12} \mathrm{Sr}_{1.8} \mathrm{Mn}_{2} \mathrm{O}_{7-\delta}$, as confirmed by XRD and EELS (Figure 3b, 3c). 

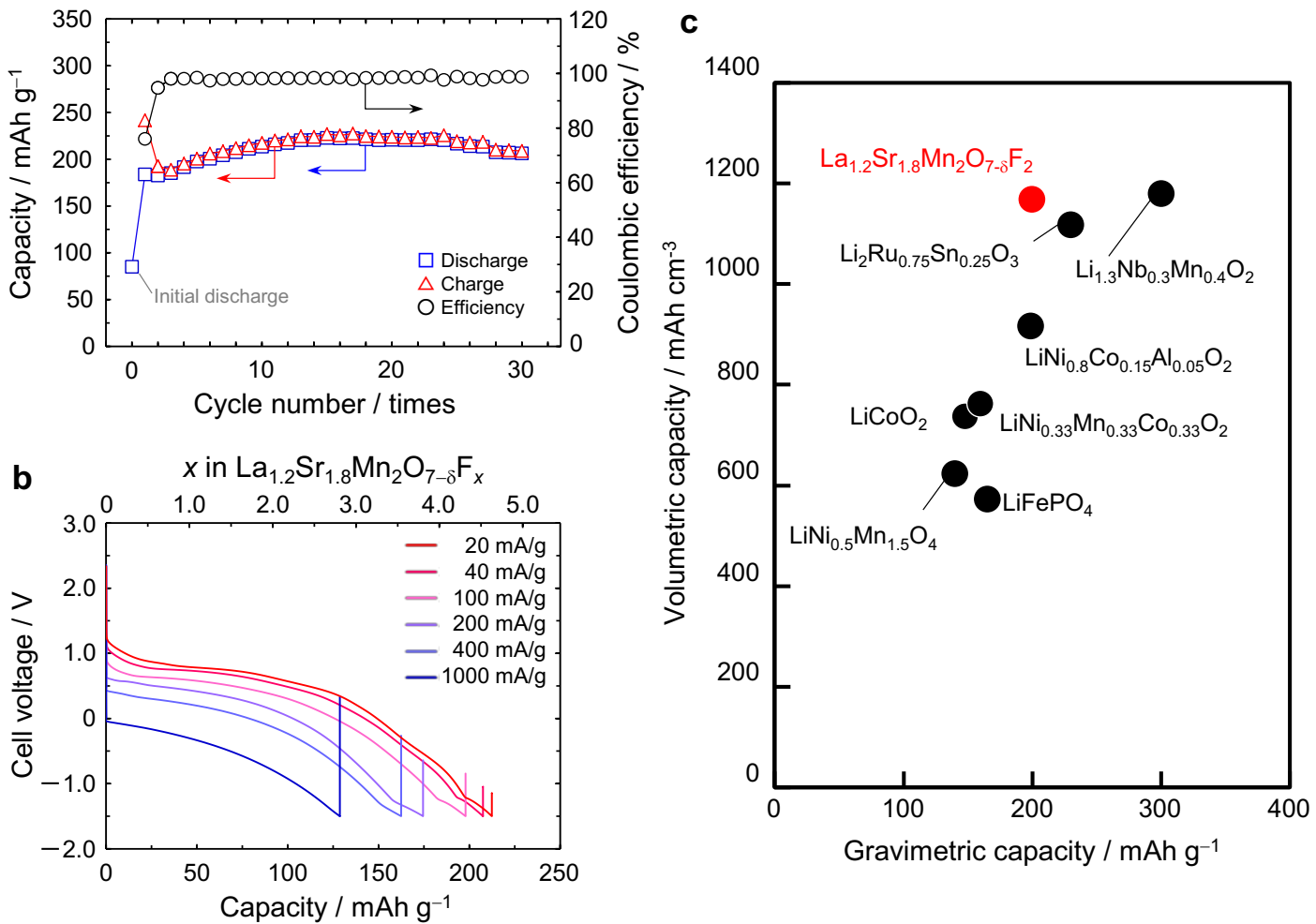

Figure 4 I Electrochemical properties of $\mathbf{L a}_{12} \mathbf{S r}_{18} \mathbf{M n}_{2} \mathrm{O}_{1-5} \mathbf{F}_{2}$ upon further fluorination. a, Cycle performance of discharge/charge capacities and the efficiency. The efficiency was calculated as follows: the $n$-th discharge capacity divided by the $n$ th charge capacity. $\mathbf{b}$, Discharge curves with different current rates for $\mathrm{La}_{12} \mathrm{Sr}_{18} \mathrm{Mn}_{2} \mathrm{O}_{1-5} \mathrm{~F}_{2}$ after 15 cycles. The same conditions were adopted for charging, with an upper limit potential of $3.0 \mathrm{~V}$ and a current rate of $10 \mathrm{~mA} / \mathrm{g}$. c, Plots of the volumetric/gravimetric capacities for $\mathrm{La}_{12} \mathrm{Sr}_{18} \mathrm{Mn}_{2} \mathrm{O}_{7-8} \mathrm{~F}_{2}$ and cathode materials reported in $\mathrm{LIBs}^{8,1239400}$. 
The capacity of each cycle provides about $200 \mathrm{mAh} / \mathrm{g}$ (four electrons reaction), and the capacity reversibility of the charge/discharge remains close to $100 \%$ as shown in Figure 4a, except for the first discharge/charge process at $80 \%$ efficiency. The origin of the irreversible charge capacity on the 1 st cycle is not clear, but may include side reactions such as the decomposition of the solid electrolyte $\mathrm{La}_{0 .} \mathrm{Ba}_{0.1} \mathrm{~F}_{29}$ (Supplementary Figure 10) and partial oxygen release as reported in $\mathrm{LIBS}^{4+43}$. Discharge capacities increase gradually with the charge-discharge cycle and remain stable for at least 30 cycles without obvious decrease in capacity, and the reversible capacity amounts to $1168 \mathrm{mAh} / \mathrm{cm}^{3}$. As shown in Figure 4c, this value is much higher than that of typical LIB cathode materials and, in terms of volumetric energy density, is comparable to that of recently investigated active materials using anion redox ${ }^{8,12}$. Figure $4 \mathrm{~b}$ shows that our material with a fluorine content varying between $x=0$ and 4 has a relatively high rate capability $(200 \mathrm{mAh} / \mathrm{g}$ at $100 \mathrm{~mA} / \mathrm{g})$, which is possibly related to the rapid fluoride ion diffusion in the bulk. 


\section{Anionic redox reactions}

The charge compensation mechanisms of (de)fluorination were examined by synchrotron hard/soft X-ray absorption spectroscopy (XAS) (Figure 5 and Supplementary Figure 13). While the La $L$ and $\operatorname{Sr} K$ absorption edges are unchanged, the $\mathrm{Mn} L$-edge peak shifts to higher energies in the early stage of fluoride ion insertion $(x<2)$ and then remains unchanged in the later stage $(2<x<4)$. These results suggest that the oxidation of $\mathrm{Mn}^{3+}$ ions occurs only in the early stage of fluoride ion insertion.

In the $\mathrm{O} K$-edge spectrum, a broad peak, which is attributed to the transitions from the $\mathrm{O} 1 s$ level to the hybridized states of the Mn $3 d$ and O $2 p$ orbitals ${ }^{4}$, was observed around $530 \mathrm{eV}$ before charging $(x \sim 0)$. The intensity at $529 \mathrm{eV}$ increased in the early stage of fluoride ion insertion $(x<2)$ (Figure $5 b$ ), which is explained by the crystalline field stabilization energy via oxidation of $\operatorname{Mn}^{3+}\left(d^{4}\right.$, high spin) to $\operatorname{Mn}^{4+}\left(d^{3}\right)$. The same behavior is seen in the Mn $L$-edge $\operatorname{spectra}^{45}$ (Figure 5a). On the other hand, further fluorination beyond $x \sim 2$ resulted in the emergence of a new $\mathrm{O} K$-edge peak at around $530.8 \mathrm{eV}$, and this peak increases its intensity with $x$, while it reversibly disappears upon fluorine deintercalation. A similar peak has been observed in peroxides such as $\mathrm{Li}_{2} \mathrm{O}_{2}^{46}$ and also in lithium-rich cathodes containing oxidized oxygen species (e.g., $\mathrm{O}^{*}$, 
$\left.\mathrm{O}_{2}^{-}, \mathrm{O}_{2^{2-}}\right)^{10,124,547}$. These observations strongly suggest that in our oxyfluoride cathode, oxidized oxygen species are involved in charge compensation during the charge/discharge process for $2<x<4$.

To further elucidate the nature of oxidized oxygen species, resonant inelastic Xray scattering (RIXS) measurements from 528.5 to $533.0 \mathrm{eV}$ in $\mathrm{O} K$-edge XAS spectra were performed (Supplementary Figure 14). The obtained RIXS spectra at $530.8 \mathrm{eV}$ (Figure 5c) exhibited discrete energy-loss peaks around the elastic line from 5 to $0 \mathrm{eV}$, representing several vibrational levels of the ground state potential energy surface ${ }^{\text {ts }}$. The frequency of the first vibrational level was approximately $1600 \mathrm{~cm}^{-1}$, similar to the gaseous molecular $\mathrm{O}_{2}$ bound with $\mathrm{Mn}^{5}$, and differed from $1108 \mathrm{~cm}^{-1}$ in $\mathrm{O}_{2-}^{-}$and $743 \mathrm{~cm}^{-1}$ in $\mathrm{O}_{2}^{4}$. Since the RIXS measurements were performed under high vacuum, this oscillatory signal is attributed most likely to $\mathrm{O}_{2}$ molecules in $\mathrm{La}_{12} \mathrm{Sr}_{1.8} \mathrm{Mn}_{2} \mathrm{O}_{7-8} \mathrm{~F}_{x}$, rather than those in the gas phase or absorbed on the cathode surface. Such $\mathrm{O}_{2}$ formation has recently been observed in $\mathrm{Na}_{0.75}\left[\mathrm{Li}_{025} \mathrm{Mn}_{0.75}\right] \mathrm{O}_{2}$ during charge process (i.e., Nadeintercalation) ${ }^{5}$. The greater polarization of the anion redox region $(x>2)$ of $\mathrm{La}_{1.2} \mathrm{Sr}_{1.8} \mathrm{Mn}_{2} \mathrm{O}_{7-5} \mathrm{~F}_{x}$ (Figure 3a) and $\mathrm{Na}_{0.75}\left[\mathrm{Li}_{025} \mathrm{Mn}_{0.75}\right] \mathrm{O}_{2}^{5}$ compared to $\mathrm{Li}_{2} \mathrm{Ru}_{0.75} \mathrm{Sn}_{025} \mathrm{O}_{3}$ (in which redox via $\mathrm{O}_{2}^{-}$occurs) ${ }^{50}$ is also in line with the formation/annihilation of $\mathrm{O}_{2}$. 
In the pre-edge region of $\mathrm{F} K$-edge spectra (Figure 5d and Supplementary Figure 15), a small peak attributed to metal-fluorine bond ${ }^{\text {si }}$ appears with the insertion of fluoride ions, and its intensity increases significantly when $x>2$, indicating that the formation of $\mathrm{O}_{2}$ is accompanied by the formation of the Mn-F bond in the perovskite blocks of $\mathrm{La}_{12} \mathrm{Sr}_{18} \mathrm{Mn}_{2} \mathrm{O}_{7-8} \mathrm{~F}_{x}$. This result explains why $\mathrm{La}_{12} \mathrm{Sr}_{18} \mathrm{Mn}_{2} \mathrm{O}_{7-8} \mathrm{~F}_{x}$ can host an excess of $\mathrm{F}$ - beyond the oxide deficiency $(\delta \sim 0.4)$ : the formation of $\mathrm{O}_{2}$ is not only responsible for oxidation, but also creates additional anion vacancies and allow excess fluoride ions to fill these sites. Note that similar molecular-like $\mathrm{O}_{2}$ state are formed in electrode materials of sodium ion battery during charge (i.e., Na-deintercalation) process ${ }^{5}$. The formation of four-electron oxidized $\mathrm{O}_{2}$ rather than $\mathrm{O}_{2}$ or $\mathrm{O}_{2}{ }^{2-}$ may be related to the shorter intramolecular distance of $\mathrm{O}_{2}$, which makes it easier to fit into the perovskite space. It is currently unclear, for example, at which oxygen sites in the perovskite slab the molecular-like $\mathrm{O}_{2}$ states are produced, for which, e.g., an operando STEM observation is required. 
a

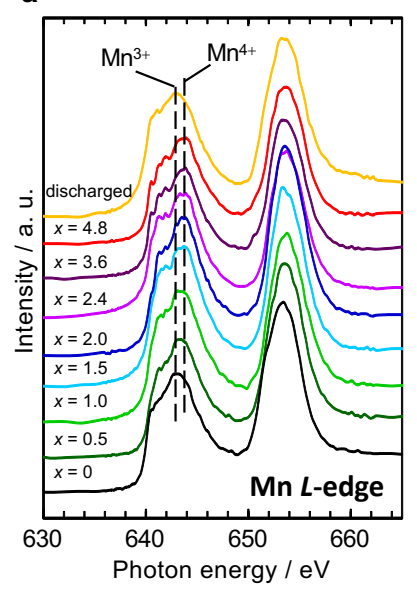

b
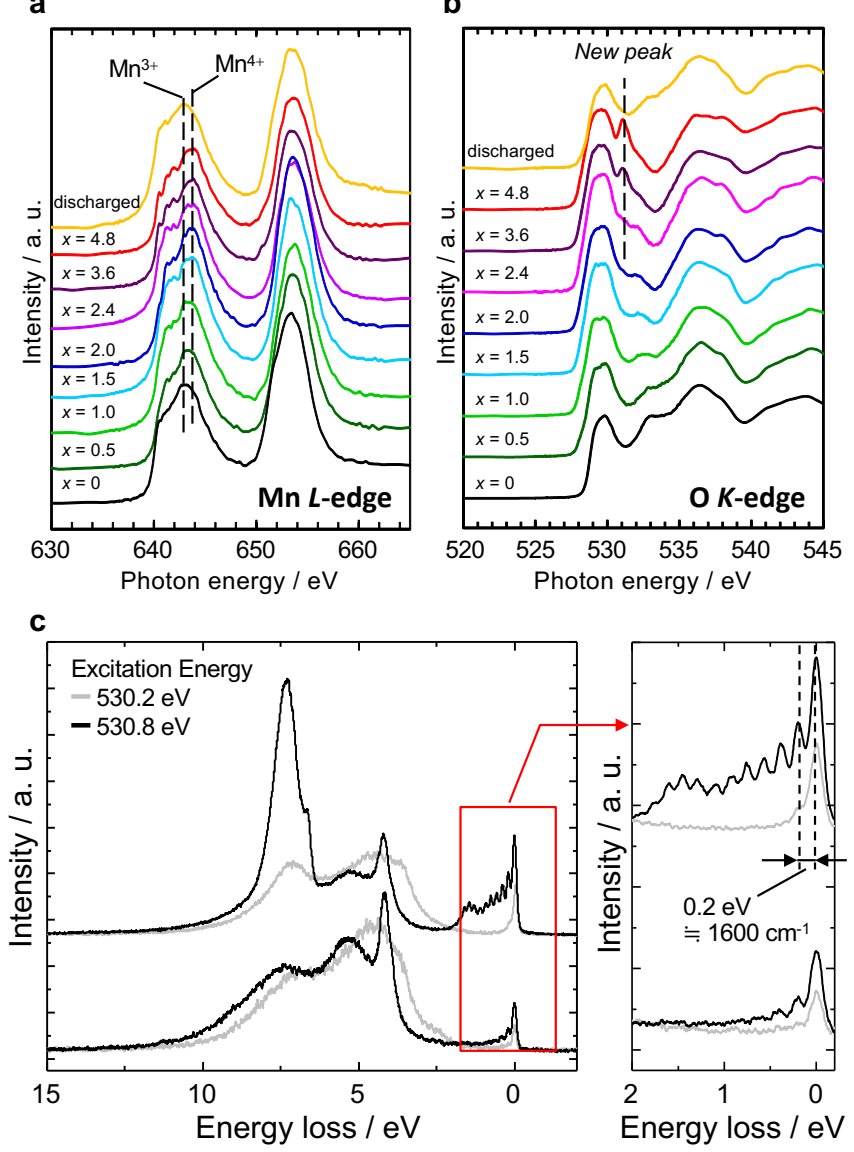

d

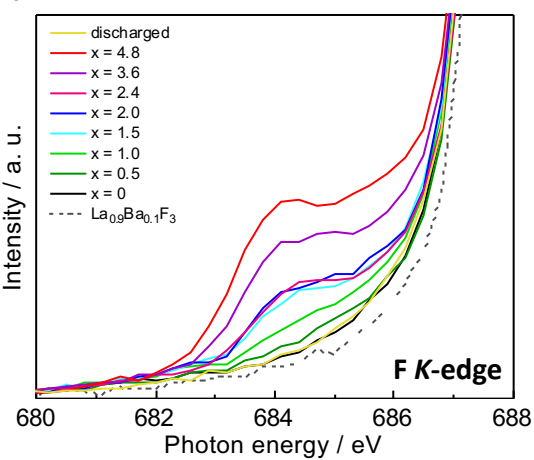

Figure 5 I Changes in electronic structures for $\mathbf{L a}_{12} \mathbf{S r}_{1 s} \mathbf{M n}_{2} \mathbf{O}_{1-5} \mathbf{F}_{2}$ on 1 st charge/discharge process. a, b, Changes in XAS spectra collected for various states in charge/discharge profiles shown in Figure 3a. a, Mn $L$-edge absorption and b, O $K$ edge absorption. The $x$ in the figure represents the fluoride content $\left(x\right.$ in $\mathrm{La}_{12} \mathrm{Sr}_{18} \mathrm{Mn}_{2} \mathrm{O}_{7}$ ${ }_{0} \mathrm{~F}_{x}$ ). c, Oxygen $K$-edge XAS and high-resolution RIXS spectra recorded at excitation energies of 530.2 and $530.8 \mathrm{eV}$ for in (lower) pristine and (upper) charged (3.0 V) states, respectively. The vibrational frequency of around $1600 \mathrm{~cm}^{-1}$ indicates the presence of $\mathrm{O}_{2}$. d, F $K$-edge absorption, indicating the formation of $\mathrm{Mn}-\mathrm{F}$ bond at $x>$ 2 . 


\section{Outlook for intercalation-type active material}

We demonstrated electrochemical intercalation of fluoride ions with excellent reversibility, cyclability and rate capability, using the double-layered RuddlesdenPopper type perovskite oxyfluoride $\mathrm{La}_{12} \mathrm{Sr}_{18} \mathrm{Mn}_{2} \mathrm{O}_{7-5} \mathrm{~F}_{x}$. Interestingly, in addition to the conventional $\mathrm{Mn}$ redox at $0<x<2$, this oxyfluoride can incorporate excess fluoride ions $(2<x<4)$ into the perovskite blocks by forming molecular $\mathrm{O}_{2}$ species (anion redox). It should be emphasized that, like the LIB, the current FIB has room for further improvement in terms of electrochemical properties such as cycle stability, rate characteristics, and fluoride ion diffusion; available strategies include chemical substitution with other transition metals, optimization of composition in an electrode mixture and tuning particle morphologies, in addition to modification of solid-solid interfaces with solid electrolytes (e.g., surface coating, orientation control).

Given the variety of structures and compositions known for conventional perovskite materials, the ability to capture excess fluorine ion through the formation of $\mathrm{O}_{2}$ molecules adds a new dimension to perovskite engineering not only for battery research but also for other disciplines. In fact, formation of molecules at the anion site in perovskite $\mathrm{ABO}_{3}$ with the 'closed packed' structure is not obvious, as seen in the 
theoretically predicted $\mathrm{H}_{2}$ molecule in $\mathrm{SrTiO}_{3}^{\text {s2 }}$, and could be an interesting research topic in general. Furthermore, this study sufficiently raises awareness that electrochemistry is a powerful tool for obtaining novel oxyfluorides and, more generally, mixed-anion compounds ${ }^{53}$ that could have an impact on a variety of physical and chemical functions.

\section{Reference}

1. Reddy, M. A. \& Fichtner, M. Batteries based on fluoride shuttle. J. Mater. Chem. 21, 17059-17062 (2011).

2. Gschwind, F., Rodriguez-Garcia, G., Sandbeck, D. J. S., Gross, A., Weil, M., Fichtner, M. \& Hormann, N. Fluoride ion batteries: Theoretical performance, safety, toxicity, and a combinatorial screening of new electrodes. J. Fluorine Chem. 182, 76-90 (2016).

3. Thieu, D. T., Fawey, M. H., Bhatia, H., Diemant, T., Chakravadhanula, V. S. K., Behm, R. J., Kübel, C. \& Fichtner, M. $\mathrm{CuF}_{2}$ as reversible cathode for fluoride ion batteries. Adv. Funct. Mater. 27, 1701051 (2017).

4. Rongeat, C., Reddy, M. A., Diemant, T., Behm, R. J. \& Fichtner, M. Development of new anode composite materials for fluoride ion batteries. J. Mater. Chem. A 2, 20861-20872 (2014).

5. House, R. A., Maitra, U., Pérez-Osorio, M. A., Lozano, J. G., Jin, L., Somerville, J. W., Duda, L. C., Nag, A., Walters, A., Zhou, K.-J., Roberts, M. R. \& Bruce, P. G. Superstructure control of first-cycle voltage hysteresis in oxygen-redox cathodes. Nature $\mathbf{5 7 7}, 502-508$ (2020).

6. Assat, G. \& Tarascon, J.-M. Fundamental understanding and practical challenges of anionic redox activity in Li-ion batteries. Nat. Energy $\mathbf{3}$, 373-386 (2018).

7. Dunn, B., Kamath, H. \& Tarascon, J.-M. Electrical Energy Storage for the Grid: A Battery of Choices. Science 334, 928-935 (2011).

8. Sathiya, M., Rousse, G., Ramesha, K., Laisa, C. P., Vezin, H., Sougrati, 
M. T., Doublet, M.-L., Foix, D., Gonbeau, D., Walker, W., Prakash, A. S., Hassine, M. Ben, Dupont, L. \& Tarascon, J.-M. Reversible anionic redox chemistry in high-capacity layered-oxide electrodes. Nat. Mater. 12, 827-835 (2013).

9. McCalla, E., Abakumov, A. M., Saubanère, M., Foix, D., Berg, E. J., Rousse, G., Doublet, M.-L., Gonbeau, D., Noval, P., Tendeloo, G. V., Dominko, R. \& Tarascon, J.-M. Visualization of O-O peroxo-like dimers in high-capacity layered oxides for Li-ion batteries. Science 350, 15161512 (2015).

10. Luo, K., Roberts, M. R., Hao, R., Guerrini, N., Pickup, D. M., Liu, Y.S., Edstrom, K., Guo, J., Chadwick, A. V., Duda, L. C. \& Bruce, P. G. Charge-compensation in $3 \mathrm{~d}$-transition-metal-oxide intercalation cathodes through the generation of localized electron holes on oxygen. Nat. Chem. 8, 684-691 (2016).

11. Seo, D.-H., Lee, J., Urban, A., Malik, R., Kang, S.\& Ceder, G. The structural and chemical origin of the oxygen redox activity in layered and cation-disordered Li-excess cathode materials. Nat. Chem. 8, 692697 (2016).

12. Yabuuchi, N., Nakayama, M., Takeuchi, M., Komaba, S., Hashimoto, Y., Mukai, T., Shiiba, H., Sato, K., Kobayashi, Y., Nakao, A., Yonemura, M., Yamanaka, K., Mitsuhara, K. \& Ohta, T. Origin of stabilization and destabilization in solid-state redox reaction of oxide ions for lithium-ion batteries. Nat. Commun. 7, 13814 (2016).

13. Pearce, P. E., Perez, A. J. Rousse, G., Saubanère, M., Batuk, D., Foix, D., McCalla, E., Abakumov, A. M., Tendeloo, G. V.\& Doublet, M.-L., Tarascon, J.-M. Evidence for anionic redox activity in a tridimensionalordered Li-rich positive electrode $\beta-\mathrm{Li}_{2} \mathrm{IrO}_{3}$. Nat. Mater. 16, 580-586 (2017).

14. Perez, A. J., Jacquet, Q., Batuk, D., Iadecola, A., Saubanère, M., Rousse, G., Larcher, D., Vezin, H., Doublet, M.-L.\& Tarascon, J.-M.

Approaching the limits of cationic and anionic electrochemical activity with the Li-rich layered rocksalt $\mathrm{Li}_{3} \mathrm{IrO}_{4}$. Nat. Energy 2, 954-962 (2017).

15. Ben Yahia, M., Vergnet, J., Saubanère, M. \& Doublet, M.-L. Unified picture of anionic redox in Li/Na-ion batteries. Nat. Mater. 18, 496-502 (2019).

16. Kato, Y., Hori, S., Saito, T., Suzuki, K., Hirayama, M., Mitsui, A., 
Yonemura, M., Iba, H. \& Kanno, R. High-power all-solid-state batteries using sulfide superionic conductors. Nat. Energy 1, 16030 (2016).

17. Kamaya, N., Homma, K., Yamakawa, Y., Hirayama, M., Kanno, R., Yonemura, M., Kamiyama, T., Kato, Y., Hama, S., Kawamoto K. \& Mitsui, A. A lithium superionic conductor. Nat. Mater. 10, 682-686 (2011).

18. Bruce, P. G., Freunberger, S. A., Hardwick, L. J. \& Tarascon, J.-M. LiO 2 and Li-S batteries with high energy storage. Nat. Mater. 11, 19-29 (2012).

19. Lee, J. S. et al. Lee, J. S., Kim, S. T., Cao, R., Choi, N. S., Liu, M., Lee, K. T., Cho, J. Metal-Air Batteries with High Energy Density: Li-Air versus Zn-Air. Adv. Energy Mater. 1, 34-50 (2011).

20. Winsberg, J., Hagemann, T., Janoschka, T., Hager, M. D. \& Schubert, U. S. Redox-Flow Batteries: From Metals to Organic Redox-Active Materials. Angew. Chem., Int. Ed. 56, 686-711 (2017).

21. Kim, S. W., Seo, D. H., Ma, X., Ceder, G. \& Kang, K. Electrode Materials for Rechargeable Sodium-Ion Batteries: Potential Alternatives to Current Lithium-Ion Batteries. Adv. Energy Mater. 2, 710-721 (2012).

22. Aurbach, D., Lu, Z., Schechter, A., Gofer, Y., Gizbar, H., Turgeman, R., Cohen, Y., Moshkovich, M. \& Levi, E. Prototype systems for rechargeable magnesium batteries. Nature 407, 724-727 (2000).

23. Zhao, X., Ren, S., Bruns, M. \& Fichtner, M. Chloride ion battery: A new member in the rechargeable battery family. J. Power Sources. 245, 706711 (2014).

24. Davis, V. K., Bates, C. M., Omichi, K., Savoie, B. M., Momčilović, N., Xu, Q., Wolf, W. J., Webb, M. A., Billings, K. J., Chou, N. H., Alayoglu, S., McKenney, R. K., Darolles, I. M., Nair, N. G., Hightower, A., Rosenberg, D., Ahmed, M., Brooks, C. J., Miller III, T. F., Grubbs, R. H. \& Jones, S. C. Room-temperature cycling of metal fluoride electrodes: Liquid electrolytes for high-energy fluoride ion cells. Science 362, 11441148 (2018).

25. Okazaki, K., Uchimoto, Y., Abe, T. \& Ogumi, Z. Charge-Discharge behavior of Bismuth in a liquid electrolyte for rechargeable batteries based on a fluoride shuttle. ACS Energy Lett. 2, 1460-1464 (2017).

26. Bard, A. J., Parsons, R. \& Jordan, J. Standard potentials in aqueous 
solution. New York, M. Dekker (1985).

27. Tsujimoto, Y., Yamaura, K. \& Takayama-Muromachi, E. Oxyfluoride chemistry of layered perovskite compounds. Appl. Sci. 2, 206-219 (2012).

28. Greaves, C., Kissick, J. L., Francesconi, M. G., Aikens, L. D. \& Gillie, L. J. Synthetic strategies for new inorganic oxide fluorides and oxide sulfates. J. Mater. Chem. 9, 111-116 (1999).

29. Li, R. K. \& Greaves, C. Double-layered ruthenate $\mathrm{Sr}_{3} \mathrm{Ru}_{2} \mathrm{O}_{7} \mathrm{~F}_{2}$ formed by fluorine insertion into $\mathrm{Sr}_{3} \mathrm{Ru}_{2} \mathrm{O}_{7}$. Phys. Rev. B 62, 3811-3815 (2000).

30. Sivakumar, T. \& Wiley, J. B. Topotactic route for new layered perovskite oxides containing fluorine: $\mathrm{Ln}_{12} \mathrm{Sr}_{18} \mathrm{Mn}_{2} \mathrm{O}_{7} \mathrm{~F}_{2}(\mathrm{Ln}=\mathrm{Pr}, \mathrm{Nd}, \mathrm{Sm}, \mathrm{Eu}$, and Gd). Mater. Res. Bull. 44, 74-77 (2009).

31. Zhang, R., Read, G., Lang, F., Lancaster, T., Blundell, S. J., \& Hayward, M. A. $\mathrm{La}_{2} \mathrm{SrCr}_{2} \mathrm{O}_{7} \mathrm{~F}_{2}$ : A Ruddlesden-Popper oxyfluoride containing octahedrally coordinated $\mathrm{Cr}^{4+}$ centers. Inorg. Chem. 55, 3169-3174 (2016).

32. Mizushima, K., Jones, P. C., Wiseman, P. J. \& Goodenough, J. B. $\mathrm{Li}_{x} \mathrm{CoO}_{2}(0<\mathrm{x} \leq 1)$ : A new cathode material for batteries of high energy density. Mater. Res. Bull. 15, 783-789 (1980).

33. Yabuuchi, N. \& Ohzuku, T. Novel lithium insertion material of $\mathrm{LiCo}_{13} \mathrm{Ni}_{13} \mathrm{Mn}_{13} \mathrm{O}_{2}$ for advanced lithium-ion batteries. J. Power Sources 119-121, 171-174 (2003).

34. Nowroozi, M. A., Wissel, K., Rohrer, J., Munnangi, A. R. \& Clemens, $\mathrm{O} . \mathrm{LaSrMnO}_{4}$ : Reversible Electrochemical Intercalation of Fluoride Ions in the Context of Fluoride Ion Batteries. Chem. Mater. 29, 3441-3453 (2017).

35. Nowroozi, M. A., Ivlev, S., Rohrer, J. \& Clemens, O. $\mathrm{La}_{2} \mathrm{CoO}_{4}$ : a new intercalation based cathode material for fluoride ion batteries with improved cycling stability. J. Mater. Chem. A 6, 4658-4669 (2018).

36. Vasala, S., Jakob, A., Wissel, K., Waidha, A. I., Alff, L.\& Clemens, O. Reversible Tuning of Magnetization in a Ferromagnetic RuddlesdenPopper-Type Manganite by Electrochemical Fluoride-Ion Intercalation. Adv. Electron. Mater. 6, 1900974-9 (2020).

37. Jiang, M., Key, B., Meng, Y. S. \& Grey, C. P. Electrochemical and structural study of the layered, 'Li-excess' lithium-ion battery electrode material Li $\left[\mathrm{Li}_{199} \mathrm{Ni}_{13} \mathrm{Mn}_{59}\right] \mathrm{O}_{2}$. Chem. Mater. 21, 2733-2745 (2009). 
38. Koga, H., Croguennec, L., Ménétrier, M., Douhil, K., Belin, S., Bourgeois, L., Suard, E., Weill, F. \& Delmas, C. Reversible oxygen participation to the redox processes revealed for $\mathrm{Li}_{120} \mathrm{Mn}_{0.54} \mathrm{Co}_{0.13} \mathrm{Ni}_{0.13} \mathrm{O}_{2} . J$. Electrochem. Soc. 160, A786-A792 (2013).

39. Nitta, N., Wu, F., Lee, J. T. \& Yushin, G. Li-ion battery materials: present and future. Materials Today 18, 252-264 (2015).

40. Julien, C. M. \& Mauger, A. Review of 5-V electrodes for Li-ion batteries: status and trends. Ionics 19, 951-988 (2013).

41. Xiao, R., Li, H. \& Chen, L. Density Functional Investigation on $\mathrm{Li}_{2} \mathrm{MnO}_{3}$. Chem. Mater. 24, 4242-4251 (2012).

42. Chen, H. \& Islam, M. S. Lithium Extraction Mechanism in Li-Rich $\mathrm{Li}_{2} \mathrm{MnO}_{3}$ Involving Oxygen Hole Formation and Dimerization. Chem. Mater. 28, 6656-6663 (2016).

43. House, R. A., Maitra, U., Jin, L., Lozano, J. G., Somerville, J. W., Rees, N. H., Naylor, A. J., Duda, L. C., Massel, F., Chadwick, A. V., Ramos, S., Pickup, D. M., McNally, D. E., Lu, X., Schmitt, T., Roberts, M. R. \& Bruce, P. G. What Triggers Oxygen Loss in Oxygen Redox Cathode Materials? Chem. Mater. 31, 3293-3300 (2019).

44. Yoon, W.-S., Balasubramanian, M., Chung, K. Y., Yang, X.-Q., McBreen, J., Grey, C. P. \& Fischer, D. A. Investigation of the charge compensation mechanism on the electrochemically Li-Ion deintercalated $\mathrm{Li}_{1 \times 1} \mathrm{Co}_{13} \mathrm{Ni}_{13} \mathrm{Mn}_{13} \mathrm{O}_{2}$ electrode system by combination of soft and hard $\mathrm{X}$ ray absorption spectroscopy. J. Am. Chem. Soc. 127, 17479-17487 (2005).

45. Yamamoto, K., Zhou, Y., Yabuuchi, N., Nakanishi, K., Yoshinari, T., Kobayashi, T., Kobayashi, Y., Yamamoto, R., Watanabe, A., Orikasa, Y., Tsuruta, K., Park, J., Byon, H. R., Tamenori, Y., Ohta, T.\& Uchimoto. Y. Charge Compensation Mechanism of Lithium-excess Metal Oxides with Different Covalent and Ionic Characters revealed by Operando Soft and Hard X-ray Absorption Spectroscopy. Chem. Mater. 32, 139 - 147 (2020).

46. Qiao, R., Chuang, Y.-D., Yan, S. \& Yang, W. Soft x-ray irradiation effects of $\mathrm{Li}_{2} \mathrm{O}_{2}, \mathrm{Li}_{2} \mathrm{CO}_{3}$ and $\mathrm{Li}_{2} \mathrm{O}$ revealed by absorption spectroscopy. PLOS ONE 7, e49182 (2012).

47. Oishi, M., Yamanaka, K., Watanabe, I., Shimoda, K., Matsunaga, T., Arai, H., Ukyo, Y., Uchimoto, Y., Ogumi, Z. \& Ohta, T. Direct 
observation of reversible oxygen anion redox reaction in Li-rich manganese oxide, $\mathrm{Li}_{2} \mathrm{MnO}_{3}$, studied by soft X-ray absorption spectroscopy. J. Mater. Chem. A 4, 9293-9302 (2016).

48. Hennies, F., Pietzsch, A., Berglund, M., Fohlisch, A., Schmitt, T., Strocov, V., Karlsson, H. O., Andersson, J.\& Rubensson, J. E. Resonant inelastic scattering spectra of free molecules with vibrational resolution. Phys. Rev. Lett. 104, 193002 (2010).

49. Radjenovic, P. M. \& Hardwick, L. J. Evaluating chemical bonding in dioxides for the development of metal-oxygen batteries: vibrational spectroscopic trends of dioxygenyls, dioxygen, superoxides and peroxides. Phys. Chem. Chem. Phys. 21, 1552-1563 (2019).

50. Assat, G., Delacourt, C., Corte, D. A. D. \& Tarascon, J.-M. Editors' Choice-Practical Assessment of Anionic Redox in Li-Rich Layered Oxide Cathodes: A Mixed Blessing for High Energy Li-Ion Batteries. J. Electrochem. Soc. 163, A2965-A2976 (2016).

51. Wang, J., Shin, Y., Arenholz, E., M. Lefler, B. M., Rondinelli, J. M. \& Steven J. May, S. Effect of fluoropolymer composition on topochemical synthesis of $\mathrm{SrMnO}_{3.8} \mathrm{~F}_{\gamma}$ oxyfluoride films. J. Phys. Rev. Mater. 2, 073407 (2018).

52. Iwazaki, Y., Gohda, Y.\& Tsuneyuki, S. Diversity of hydrogen configuration and its roles in $\mathrm{SrTiO}_{3-\delta}$. APL Materials 2, 012103 (2014).

53. Kageyama, H., Hayashi, K., Maeda, K., Paul Attfield, J., Hiroi, Z., Rondinelli, J. M. \& Poeppelmeier, K. R. Expanding frontiers in materials chemistry and physics with multiple anions. Nat. Commun. 9 , 772 (2018).

54. Rongeat, C., Reddy, M. A., Witter, R. \& Fichtner, M. Solid Electrolytes for Fluoride Ion Batteries: Ionic Conductivity in Polycrystalline Tysonite-Type Fluorides. ACS Appl. Mater. Interfaces 6, 2103-2110 (2014).

55. Harada, Y., Kobayashi, M., Niwa, H., Senba, Y., Ohashi, H., Tokushima, T., Horikawa, Y., Shin, S., Oshima, M. Ultrahigh resolution soft x-ray emission spectrometer at BL07LSU in SPring-8. Rev. Sci. Instrum. 83, 013116 (2012). 


\section{Methods}

Synthesis of materials. $\mathrm{La}_{12} \mathrm{Sr}_{18} \mathrm{Mn}_{2} \mathrm{O}_{7}$ was prepared by using conventional solid state reaction similar to previously described ${ }^{4}$. Reagent grade of $\mathrm{La}_{2} \mathrm{O}_{3}(99.99 \%$, Kojundo Chemical Laboratory), $\mathrm{SrCO}_{3}\left(99.9 \%\right.$, WAKO pure chemical industries, 1td.) and $\mathrm{MnO}_{2}$ (99.5\%, WAKO pure chemical industries, ltd.) were used as starting materials. These materials were weighed in a stoichiometric ratio and mixed by planetary ball-milling for $10 \mathrm{~h}$. This mixed powder was pressed into a pellet and annealed at $1400{ }^{\circ} \mathrm{C}$ for twice of $20 \mathrm{~h}$ in air with an intermediate grinding. $\mathrm{La}_{12} \mathrm{Sr}_{18} \mathrm{Mn}_{2} \mathrm{O}_{7-\mathrm{s}} \mathrm{F}_{2}$ was synthesized from chemical fluorination of $\mathrm{La}_{12} \mathrm{Sr}_{18} \mathrm{Mn}_{2} \mathrm{O}_{7}$ using polyvinylidene difluoride ( $\mathrm{PVdF}$ ) as previously reported ${ }^{30} .1 .0 \mathrm{~g}$ of the obtained $\mathrm{La}_{12} \mathrm{Sr}_{18} \mathrm{Mn}_{2} \mathrm{O}_{7}$ powder and $1.5 \mathrm{~g}$ of $\mathrm{PVdF}$ (Aldrich, average Mw: 180,000, average Mn: 71,000) were placed in separate alumina boats, covered with a sagger in an electric muffle furnace, and heated at 400 ${ }^{\circ} \mathrm{C}$ for $10 \mathrm{~h}$ under air. $\mathrm{La}_{0,9} \mathrm{Ba}_{0.1} \mathrm{~F}_{29}$, using as a solid electrolyte with fluoride-ion conductivity, was synthesized as reported in the literature ${ }^{54} . \mathrm{LaF}_{3}(99.9 \%$, Kojundo Chemical Laboratory) and $\mathrm{BaF}_{2}(99.9 \%$, Kojundo Chemical Laboratory) were mixed in a molar ratio of 9:1 and ball-milled at $600 \mathrm{rpm}$ for $12 \mathrm{~h}$ using Ar-filled $45 \mathrm{~mL} \mathrm{ZrO}_{2}$ pot and $30 \mathrm{~g}$ of $\Phi 5 \mathrm{~mm}$ balls. The mixture was annealed at $600{ }^{\circ} \mathrm{C}$ for $10 \mathrm{~h}$ in $\mathrm{Ar}$ atmosphere. 
Assembly of the all-solid-state type electrochemical cell. The cathode composite consisted of $\mathrm{La}_{12} \mathrm{Sr}_{1.8} \mathrm{Mn}_{2} \mathrm{O}_{7-5} \mathrm{~F}_{2}$ ( or $\mathrm{La}_{12} \mathrm{Sr}_{18} \mathrm{Mn}_{2} \mathrm{O}_{7}$ ) powder, $\mathrm{La}_{09} \mathrm{Ba}_{0.1} \mathrm{~F}_{29}$ powder and VaporGrown Carbon Fiber (Showa Denko, VGCF, battery grade), with mixed in a weight ratio of 30:60:10 by ball-milling for $10 \mathrm{~h}$ at $100 \mathrm{rpm}$ using $45 \mathrm{~mL}$ of $\mathrm{ZrO}_{2}$ pot and 30 $\mathrm{g}$ of $\mathrm{ZrO}_{2}$ balls. $\mathrm{La}_{0,9} \mathrm{Ba}_{0.1} \mathrm{~F}_{2,}$ and $0.2 \mathrm{~mm}$ thickness of $\mathrm{Pb}$ foil were used as a solid electrolyte and an anode, respectively. Additionally, in case of examination of further fluorination and $\mathrm{La}_{12} \mathrm{Sr}_{18} \mathrm{Mn}_{2} \mathrm{O}_{7}$ cathode, $\mathrm{PbF}_{2} /$ acetylene black (Denki Kagaku Kogyo, $\mathrm{AB}$ ) composites, mixed by ball-milling for $3 \mathrm{~h}$ at $600 \mathrm{rpm}$, are used as a fluorine source on anode side. The electrochemical cells were assembled in disk-shaped pellet by compressed cathode/solid electrolyte/anode layers. At first, $10 \mathrm{mg}$ of cathode composite and $200 \mathrm{mg}$ of $\mathrm{La}_{09} \mathrm{Ba}_{0.1} \mathrm{~F}_{29}$ were compressed heating at $120{ }^{\circ} \mathrm{C}$ for $45 \mathrm{~min}$ under 4 ton $/ \mathrm{cm}^{2}$. After that, $\mathrm{Pb}$ foil (and $\mathrm{PbF}_{2} / \mathrm{AB}$ composite) was added as an anode layer and Pt foils were added on both ends as a current collector. These layers were compressed under 4 ton $/ \mathrm{cm}^{2}$. The diameter of the pellet was $11.28 \mathrm{~mm}$. All fabrication processes of the all-solid-state type electrochemical cell were conducted under Ar atmosphere in a glovebox.

Electrochemical measurement. Assembled cells were put in a sealed container without exposing to the air atmosphere. Charge and discharge experiments of the all- 
solid-state fluoride ion cells were conducted in a potential range $-1.5 \sim 2.0$ (or $-1.5 \sim 3.0) \mathrm{V}$ vs. $\mathrm{Pb} / \mathrm{PbF}_{2}$ at $140{ }^{\circ} \mathrm{C}$ heated by mantle heater. The lower cut-off potential was set at $-1.5 \mathrm{~V}$ since $\mathrm{La}_{09} \mathrm{Ba}_{0.1} \mathrm{~F}_{29}$ (in the cathode) decompose under $-2.4 \mathrm{~V}$ vs. $\mathrm{PbF} / \mathrm{Pb}$. Unless otherwise specified, $6.7 \mathrm{~mA} / \mathrm{g}$ was applied as the current density. Rate dependence of the charge-discharge profiles were measured with various current densities at both charge and discharge process. Cyclic voltammetry was carried out with at a sweep rate of $1 \mathrm{mV} / \mathrm{sec}$. The electrochemical properties of the electrochemical test cells were collected using a potentiostat/galvanostat apparatus (VMP3, Bio-Logic Science Instruments).

Materials characterization. XRD profiles of the material were obtained using Rigaku Ultima IV using $\mathrm{Cu} \mathrm{K \alpha}$ radiation with $40 \mathrm{kV}$ of tube voltage and $40 \mathrm{~mA}$ of current. Spherical Aberration (Cs) corrected scanning transmission electron-microscope (Cscorrected STEM) observations and selected area electron diffraction (SAED) measurements were collected using JEM-ARM200F (JEOL) to characterize the crystal structures of the samples. Thin sections of the samples were fabricated by cryo-focused ion beam (cryo-FIB) micro-sampling technique using nanoDUE'T NB5000 (HITACHI). Atomic resolution electron energy loss spectroscopy (EELS) mapping and energy dispersive X-ray spectroscopy (EDX) were obtained to investigate the 
elements ordering and the position of fluorine element in the crystal structures of samples. Synchrotron XRD was measured at BL02B2 beamline in SPring-8 in Japan. X-ray absorption spectroscopy (XAS) was measured at BL14B2 and BL27SU beamlines in SPring-8 in Japan. Resonant inelastic X-ray scattering (RIXS) measurements were performed at BL07LSU in SPring-8 using a high resolution

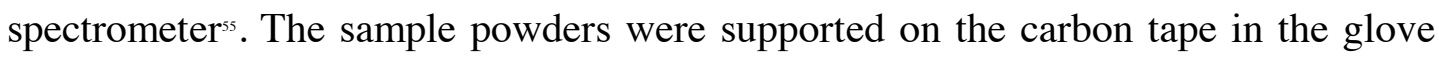
box filled with inert Ar gas and transferred to the measurement chamber without exposing atmosphere. The sample positions were changed at $2.4 \mu \mathrm{m} / \mathrm{s}$ during the RIXS measurement to avoid radiation damage. 


\section{Acknowledgements}

The authors thank Mr. Koki Terada and Mr. Kentaro Nakagawa for their support in preparation of the all-solid-state cells. We are also thankful to Dr. Hideyuki Koga and Mr. Takeshi Tojigamori for helpful discussions. The XRD, XAS experiments were performed at beamlines BL02B2, BL14B2, and BL27SU of SPring-8 with the approval of the Japan Synchrotron Radiation Research Institute (proposal nos. 2018A1276, 2018B1507, 2019A1817). The RIXS experiment at SPring-8 BL07LSU was carried out by the joint research in the Synchrotron Radiation Research Organization and the Institute for Solid State Physics, the University of Tokyo (proposal no. 2020A7487). This work was partly supported by JSPS KAKENHI “Mixed-anion”(JP16H06438, JP16H06440, JP17H0548 and JP19H04697).

\section{Author contributions}

H. M. designed and conducted the experimental work. H. M., H. N., K. Y. and T. Y. prepared materials and measured electrochemical properties. H. M. carried out the analysis of the crystal structure by XRD measurement and STEM observation. K. Y., H. N., T. Y. and K. N., with comments from Y. U., measured and analyzed XAS spectra. 
J. M. and Y. H. measured and analyzed RIXS spectra. H. M., K. Y., Y. U. and H. K. wrote the manuscript. All authors discussed the results. 


\section{Figures}

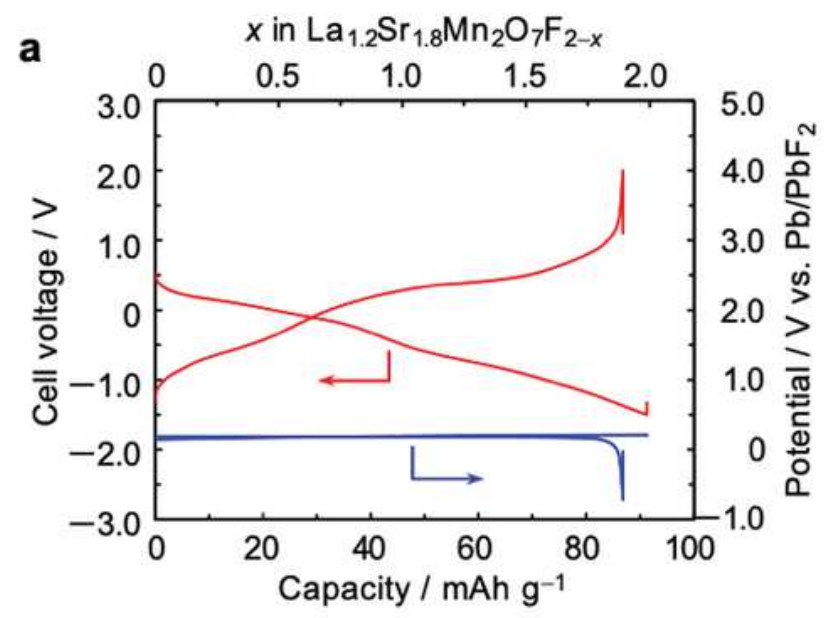

b
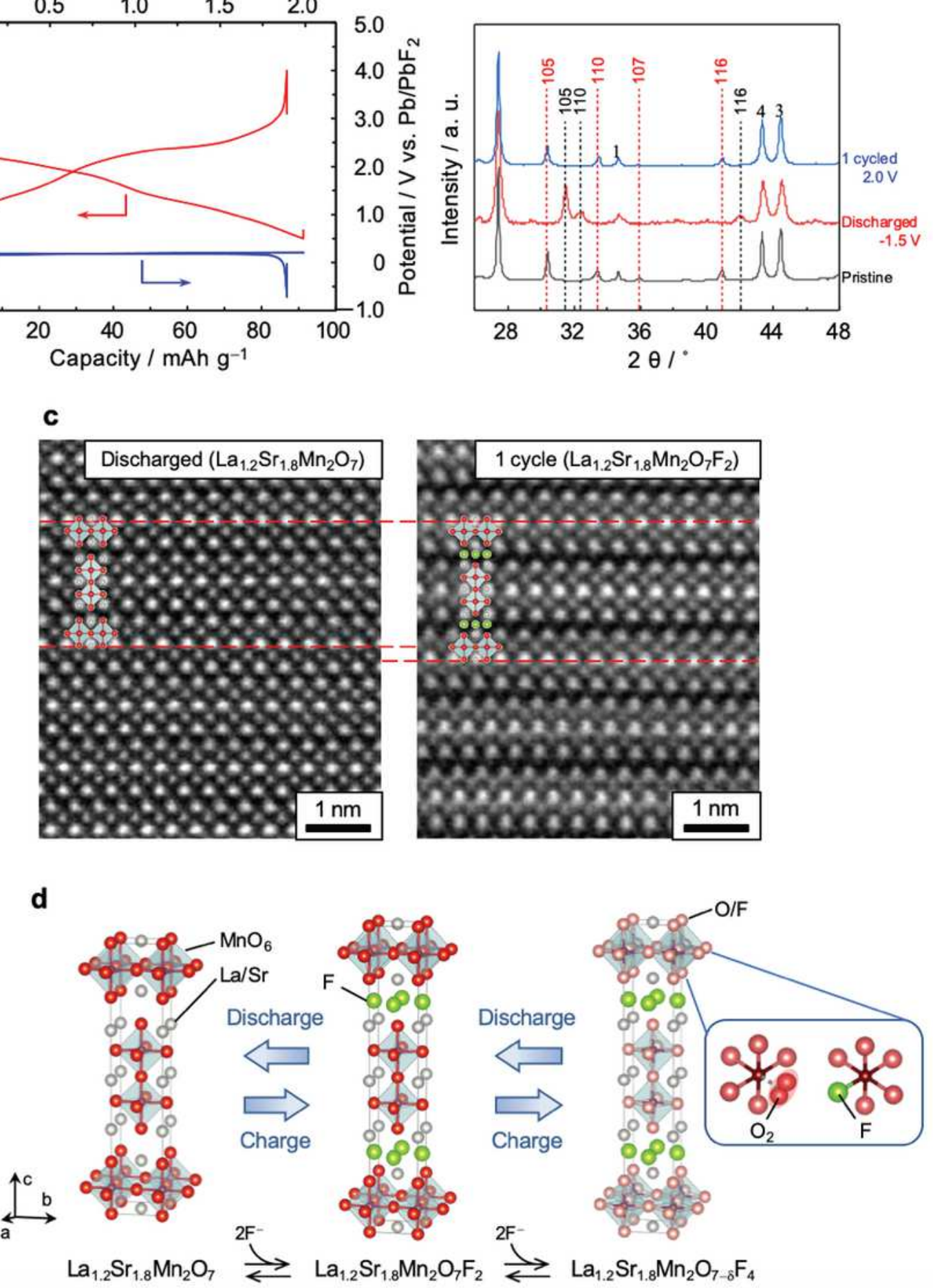

Figure 1

Electrochemical performance of La1.2Sr1.8Mn207F2 and structural changes after discharge/charge process. a, Discharge/charge curves at a rate of $10 \mathrm{~mA} / \mathrm{g}$ at $140{ }^{\circ} \mathrm{C}$, where red and blue lines show, respectively, cell voltage and potential of counter electrode. $b$, XRD patterns of cathode composites 
containing La1.2Sr1.8Mn207F2 before and after galvanostatic discharge/charge. Red and black broken lines are peaks of La1.2Sr1.8Mn2O7F2 and La1.2Sr1.8Mn207, respectively. Asterisk marks La0.9Ba0.1F2.9 (solid electrolyte). c, High-angle annular dark-field (HAADF) STEM images of La1.2Sr1.8Mn207F2 after discharge and 1 cycle viewed along [010]. d, Discharge/charge scheme of La1.2Sr1.8Mn207F2. Note that the pristine sample has an oxygen offstoichiometry of

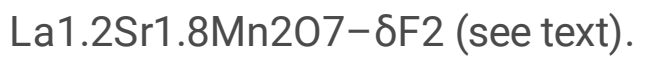
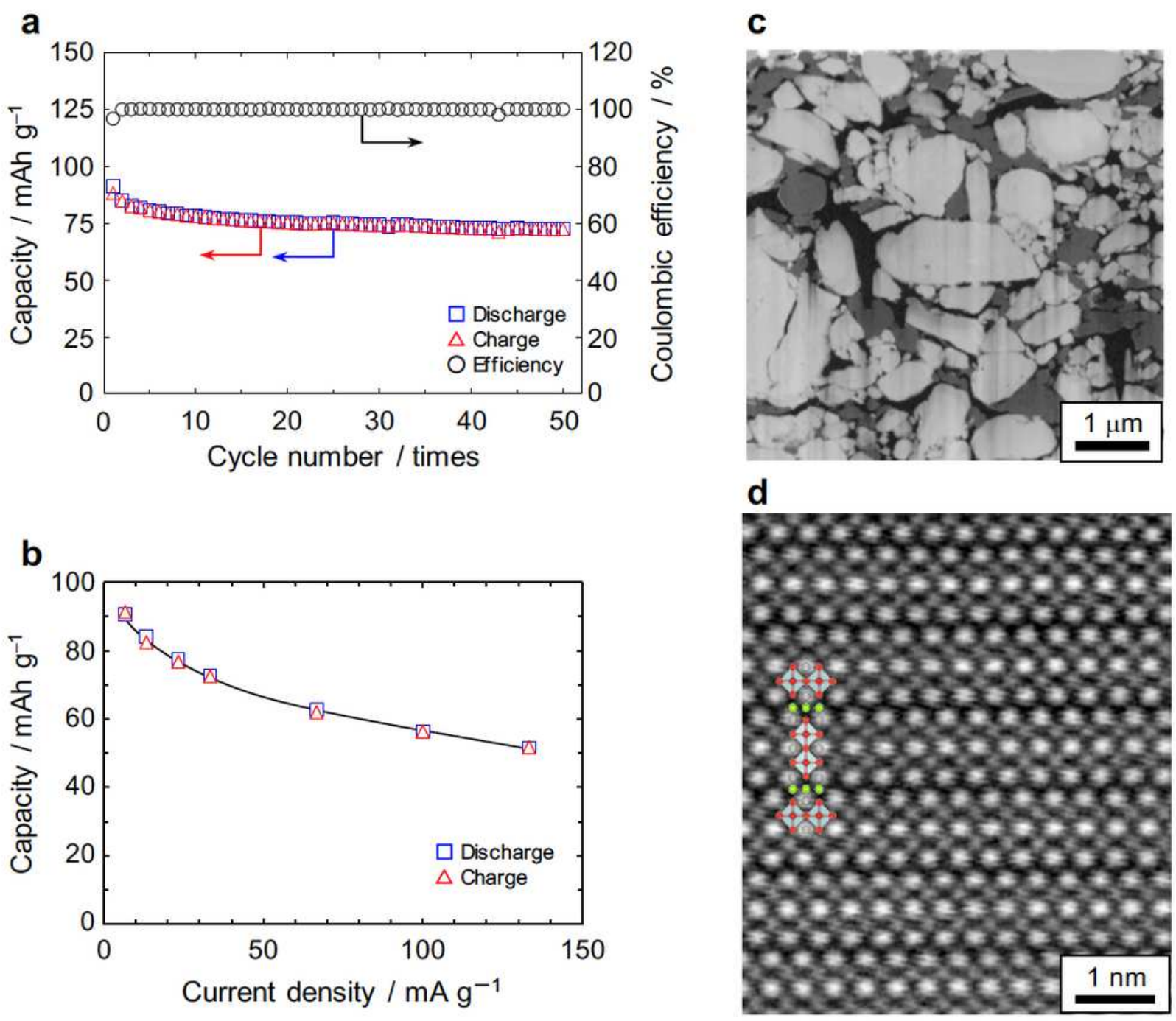

\section{Figure 2}

Cycle stability and rate performance of La1.2Sr1.8Mn207F2. a, Cycle performance of the discharge and charge capacities and the efficiencies. The efficiencies are estimated by dividing charge capacities by discharge capacities in the same cycle. b, Rate capability of La1.2Sr1.8Mn207F2, which was charged to $2.0 \mathrm{~V}$ at different rates and then discharged to $-1.5 \mathrm{~V}$ at the same rate as the charge process. c, d, HAADFSTEM images of charged La1.2Sr1.8Mn207F2 after 50 cycles, viewed along [010]. Note that the pristine sample has an oxygen off-stoichiometry of La1.2Sr1.8Mn2O7- $\delta$ F2 (see text). 


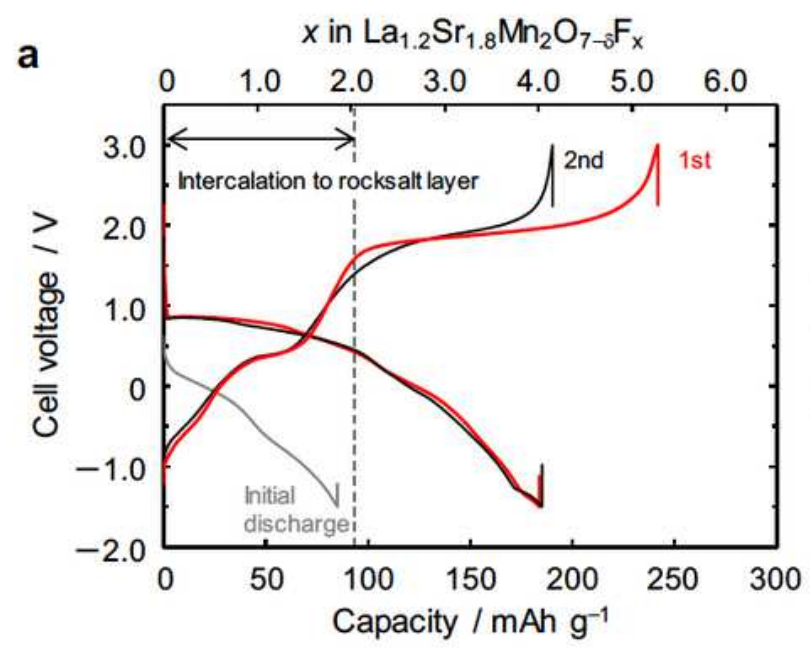

b
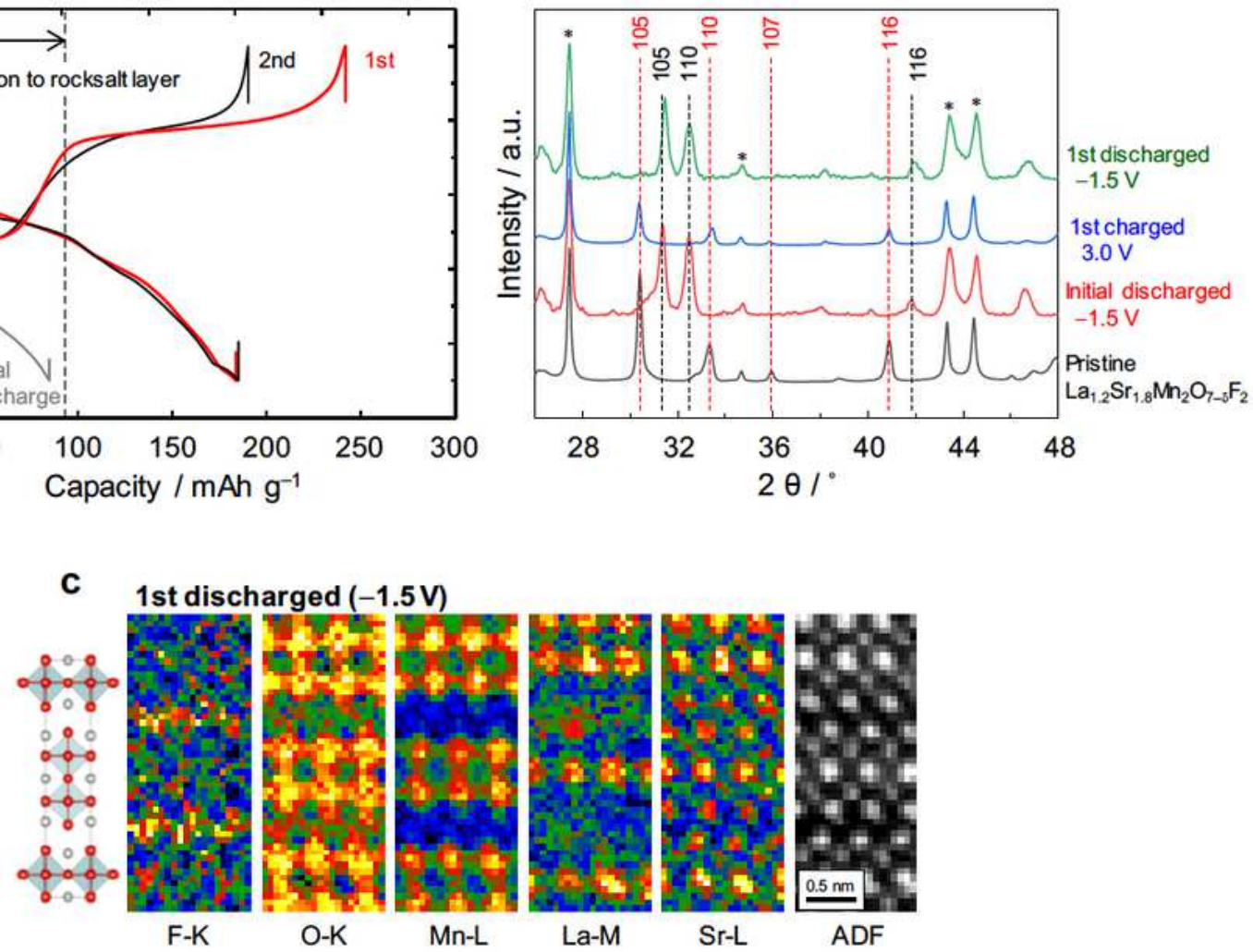

1st charged $(3.0 \mathrm{~V})$
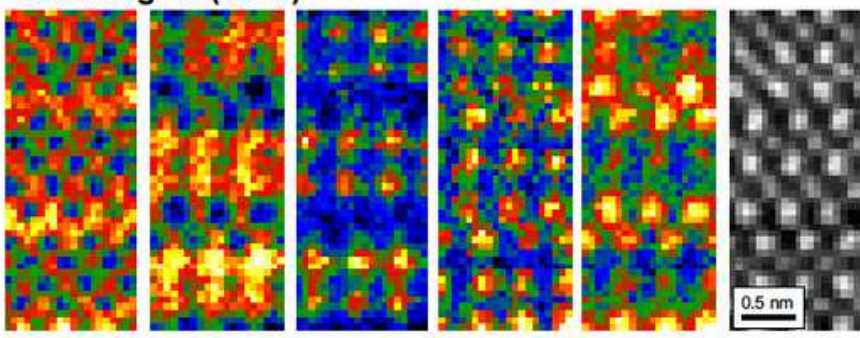

$\mathrm{F}-\mathrm{K}$

O-K

$\mathrm{Mn}-\mathrm{L}$

La-M Sr-L

ADF

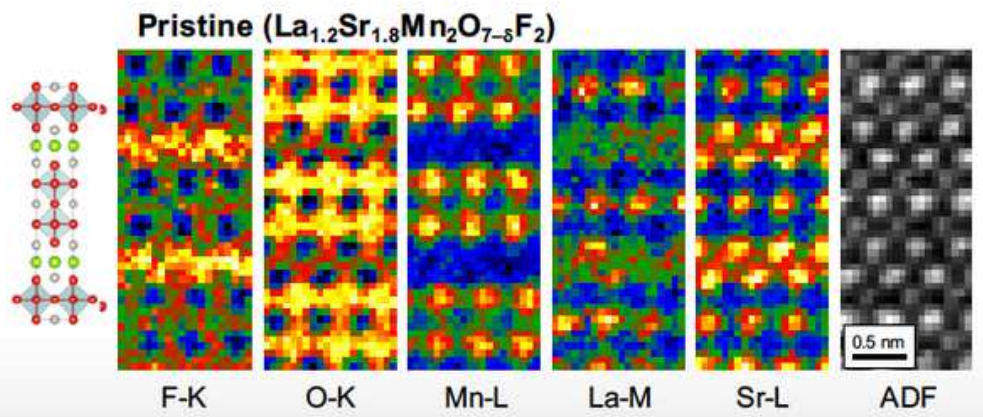

Figure 3

Charge/discharge properties and structural changes of La1.2Sr1.8Mn2O7- $\delta \mathrm{F} 2$ upon charging at higher potential. a, Charge/discharge curves at a rate of $10 \mathrm{~mA} / \mathrm{g}$ at $140^{\circ} \mathrm{C}$, where $\mathrm{PbF} 2 / \mathrm{AB}$ composite was included in the anode side between solid electrolyte and $\mathrm{Pb}$ foil as a fluorine source. $\mathrm{b}, \mathrm{XRD}$ patterns of cathode composites containing La1.2Sr1.8Mn2O7- $\delta$ F2 before and after galvanostatic charge/discharge.

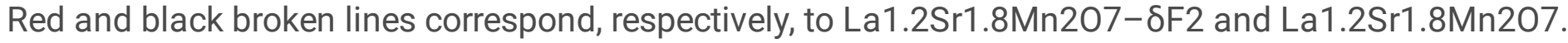


Asterisks denote La0.9Ba0.1F2.9 electrolyte. Note that in order to obtain clearer diffraction peaks for La1.2Sr1.8Mn207- $\delta F 2$, we used a cathode composite with higher active material content ( $60 \mathrm{wt} \%$ ) (see

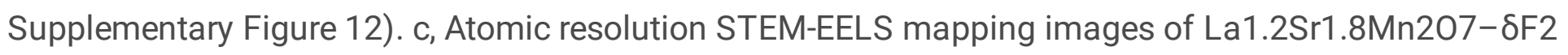
before and after galvanostatic charge/discharge, viewed along [010]. For simplicity, the ideal structures are shown.

\section{a}
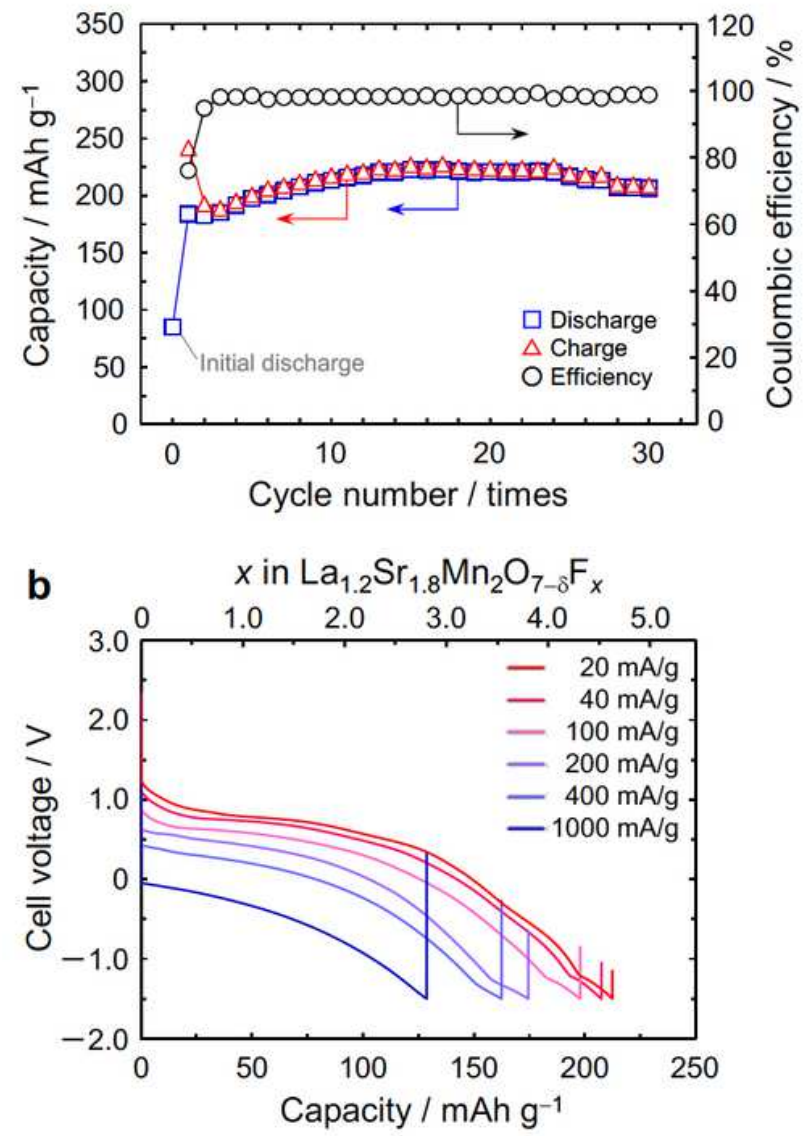

C

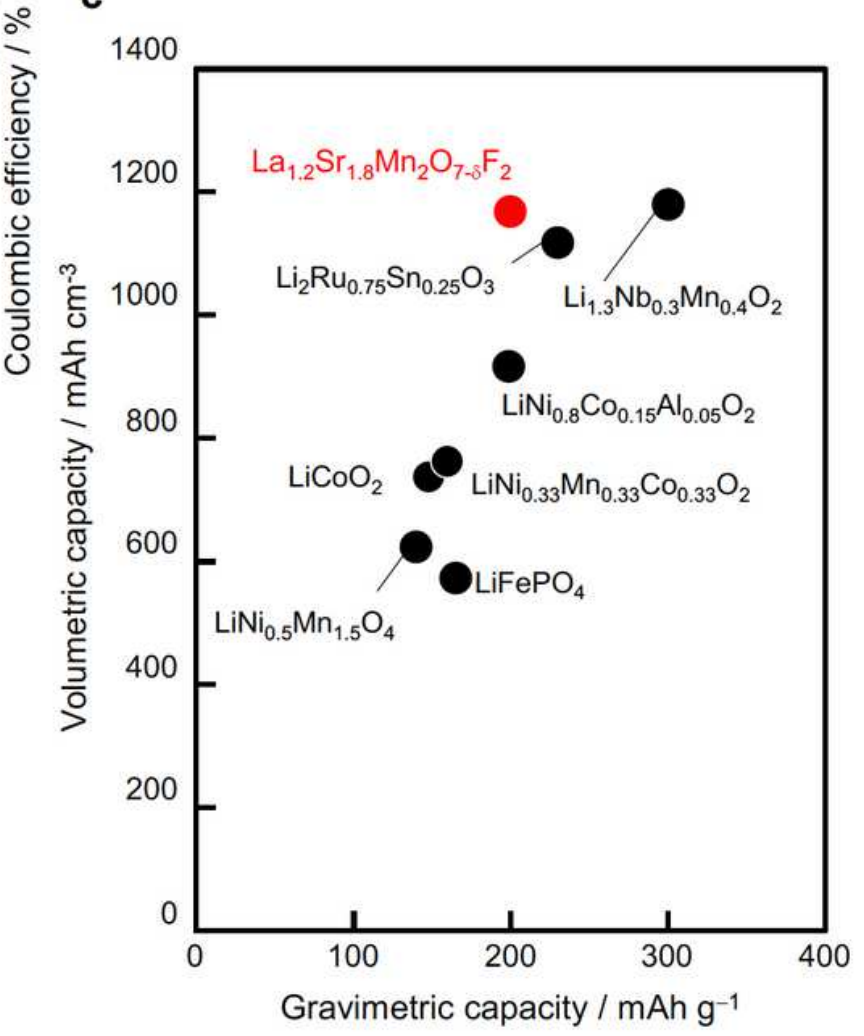

\section{Figure 4}

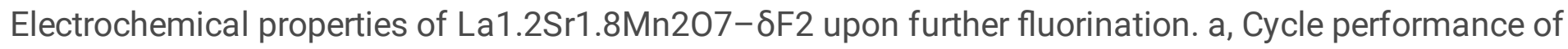
discharge/charge capacities and the efficiency. The efficiency was calculated as follows: the $\mathrm{n}$-th discharge capacity divided by the nth charge capacity. b, Discharge curves with different current rates for La1.2Sr1.8Mn207- $\delta$ F2 after 15 cycles. The same conditions were adopted for charging, with an upper limit potential of $3.0 \mathrm{~V}$ and a current rate of $10 \mathrm{~mA} / \mathrm{g}$. c, Plots of the volumetric/gravimetric capacities for

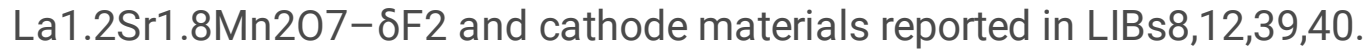


a

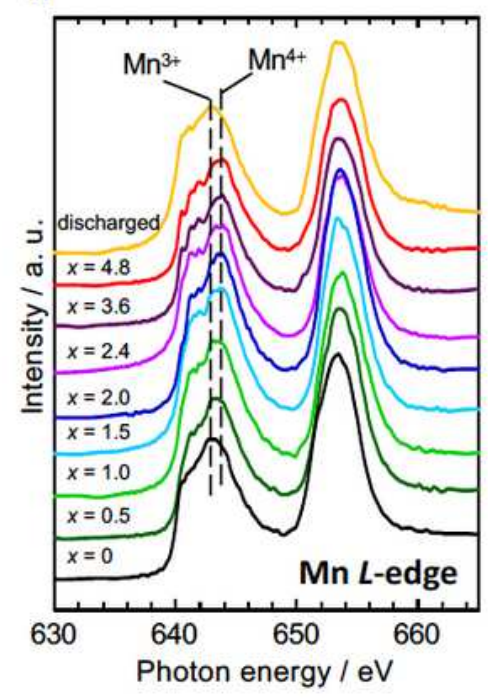

b

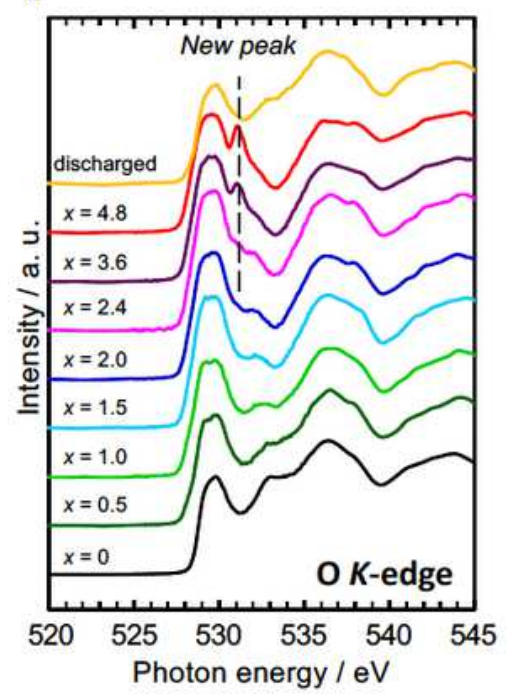

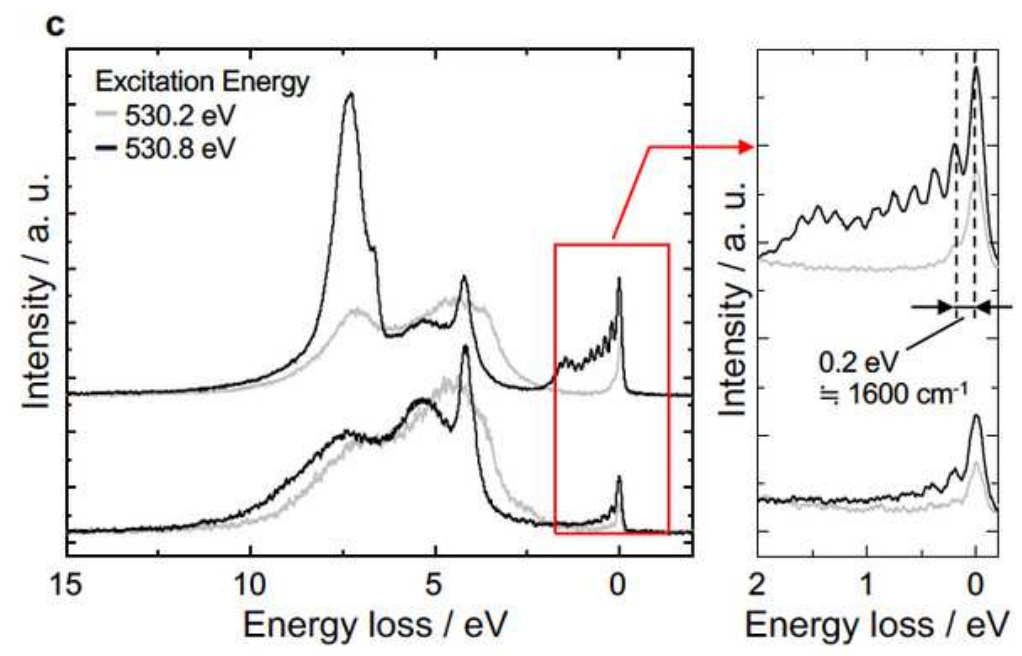

d

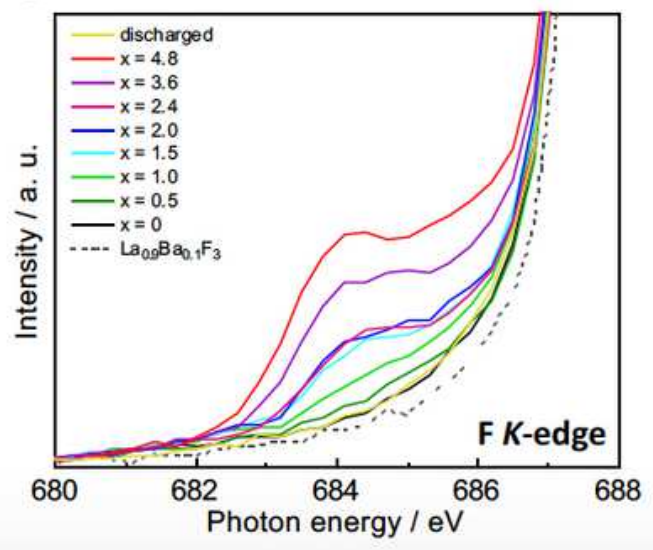

Figure 5

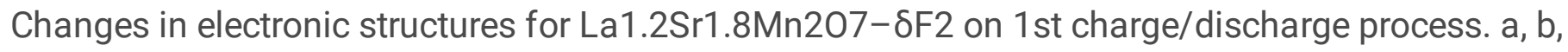
Changes in XAS spectra collected for various states in charge/discharge profiles shown in Figure 3a. a, $\mathrm{Mn}$ L-edge absorption and $\mathrm{b}, \mathrm{O}$ Kedge absorption. The $\mathrm{x}$ in the figure represents the fluoride content $\mathrm{x}$ in

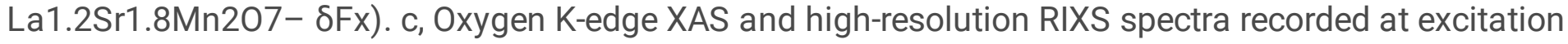
energies of 530.2 and $530.8 \mathrm{eV}$ for in (lower) pristine and (upper) charged (3.0 V) states, respectively. The 
vibrational frequency of around $1600 \mathrm{~cm}-1$ indicates the presence of 02 . d, F K-edge absorption, indicating the formation of $M n-F$ bond at $x>2$.

\section{Supplementary Files}

This is a list of supplementary files associated with this preprint. Click to download.

- 20200918SI.zip 